\title{
Conservative Nonhormonal Options for the Treatment of Male Infertility: Antibiotics, Anti-Inflammatory Drugs, and Antioxidants
}

\author{
Aldo E. Calogero, ${ }^{1}$ Rosita A. Condorelli, ${ }^{1}$ Giorgio Ivan Russo, ${ }^{2}$ and Sandro La Vignera ${ }^{1}$ \\ ${ }^{1}$ Department of Clinical and Experimental Medicine, University of Catania, Catania, Italy \\ ${ }^{2}$ Department of Surgery, Urology Section, University of Catania, Catania, Italy \\ Correspondence should be addressed to Sandro La Vignera; sandrolavignera@unict.it
}

Received 2 November 2016; Revised 4 December 2016; Accepted 5 December 2016; Published 9 January 2017

Academic Editor: Yujiang Fang

Copyright (C) 2017 Aldo E. Calogero et al. This is an open access article distributed under the Creative Commons Attribution License, which permits unrestricted use, distribution, and reproduction in any medium, provided the original work is properly cited.

\begin{abstract}
The nonhormonal medical treatment can be divided into empirical, when the cause has not been identified, and nonempirical, if the pathogenic mechanism causing male infertility can be solved or ameliorated. The empirical nonhormonal medical treatment has been proposed for patients with idiopathic or noncurable oligoasthenoteratozoospermia and for normozoospermic infertile patients. Anti-inflammatory, fibrinolytic, and antioxidant compounds, oligo elements, and vitamin supplementation may be prescribed. Infection, inflammation, and/or increased oxidative stress often require a specific treatment with antibiotics, antiinflammatory drugs, and/or antioxidants. Combined therapies can contribute to improve sperm quality.
\end{abstract}

\section{Introduction}

The nonhormonal medical treatment has a relevant role in male infertility since it may solve the cause of infertility, whereas in some other times it may ameliorate sperm parameters by improving the environment where spermatozoa are produced and mature. The nonhormonal treatment may be classified into empirical and nonempirical.

\section{Empirical Treatment}

The empirical nonhormonal medical treatment has been prescribed to patients with idiopathic oligoasthenoteratozoospermia (OAT), patients with OAT due to a noncurable disease, and normozoospermic infertile patients without identifiable risk factors for infertility. Sometimes, a slight improvement of the sperm leads to the achievement of pregnancy.

The scientific evidence of the effectiveness of such a treatment has been scanty. Anti-inflammatory, fibrinolytic, and antioxidant compounds and vitamin supplementation are used. Antioxidant treatment for subfertile couples has been also prescribed to the male partner of couples undergoing assisted reproduction techniques (ART). Further studies are required to clarify the role of these drugs [1].

\section{Nonempirical Treatment}

A nonempirical treatment has been prescribed when the cause of infertility has been identified and it has been curable. Such a treatment has been based on drugs that can specifically eradicate the etiopathogenic noxa. Aside from endocrine causes, three often coexisting conditions interfering with the reproductive function may require nonempirical treatment: infections, inflammation, and/or increased oxidative stress.

A nonempirical treatment for infertility due to urogenital tract infections has been based on the use of specific antibiotics, following identification of the microorganisms by appropriate microbiological investigation and the relative antibiogram. We can distinguish the presence of microorganisms, therefore, as microbial or inflammatory forms.

Microbial forms show the growth of more than $10^{3}$ pathogenic bacteria or more than $10^{4}$ nonpathogenic bacteria per $\mathrm{ml}$, in culture of diluted seminal plasma. Some 
Gram-negative bacteria (Enterobacteriaceae such as Escherichia coli, Klebsiella species, Proteus, Serratia, and Pseudomonas species) and etiological agents of sexually transmitted diseases (Chlamydia trachomatis, Ureaplasma urealyticum, Treponema pallidum, Neisseria gonorrhoeae, etc.) are recognized as "certain pathogens" of the prostate (category II according to the National Institutes of Health classification). On the other hand, some microorganisms of the prostate, which are occasionally detectable in the urogenital tract, are considered by some authors to be "nonpathogenic," "likely pathogens," "occasional pathogens" (Gram-positive germs, such as Enterococcus spp., Staphylococcus aureus, and obligate anaerobes), or "possible pathogens" (coagulasenegative germs, such as Staphylococcus haemolyticus, Staphylococcus epidermidis, and mycoplasmas) [2].

Recently, an elevated frequency of HPV infection in patients with infertility [3], as a viral form, cannot rely on antibiotic treatment. The most frequently used families of antimicrobial drugs for the treatment of the microbial forms are fluoroquinolones, macrolides, and tetracyclines $[4,5]$.

The inflammatory forms are characterized by leukocytospermia (seminal fluid leukocyte concentration $>10^{6} / \mathrm{mL}$ ) and/or overproduction of reactive oxygen species (ROS). An increased number of leukocytes in the seminal fluid may persist even after antibiotic treatment for a microbial form in some patients with complicated infection of the male accessory glands, such as prostatovesiculoepididymitis (PVE). In addition to leukocytospermia [6], these patients have often abnormal conventional sperm parameters (concentration, motility, and morphology) [7] and other signs of inflammation. Seminal leukocytes are predominantly polymorphonuclear leukocytes (neutrophils), but histochemistry, the technique used for their identification (based on the presence of peroxidase in granulocytes), does not detect other types of leukocytes. Other markers of inflammation are represented by some cytokines (IL-1, IL-2, IL-6, IL-8, IL-18, $\alpha \mathrm{TNF}$, and $\gamma \mathrm{INF}$ ) [8]. In these patients an anti-inflammatory treatment may be done using nonsteroidal anti-inflammatory drugs (NSAIDs) [9] that can be administered simultaneously before or after the antibiotic therapy [10] or nutraceutical compounds with anti-inflammatory and fibrinolytic properties.

The oxidative stress is another important mechanism that damages spermatozoa. It arises from an elevated production of ROS, byproducts of aerobic life, which exceeds the natural scavenger ability of spermatozoa and of the seminal fluid. In fertile men, ROS production and the total antioxidant capacity remain in balance [15]. However, infections, autoimmune disorders, chronic disease, advanced age, alcohol consumption, cigarette smoking, stress, and obesity alter this balance and increase the oxidative stress [16]. In small amount, ROS play a physiological, useful role in sperm function. Spermatozoa produce a small amount of ROS in their earliest stages of development [17]. In this phase, ROS are involved both in the process of sperm chromatin condensation and in the induction of apoptosis or proliferation of spermatogonia, in order to regulate the final number of germ cells [18]. Instead, in mature spermatozoa,
ROS are necessary to boost the capacitation process and the acrosome reaction and they are involved in mitochondrial sheath stability and sperm motility. It has been found that spermatozoa with abnormal morphology, mainly those with cytoplasmic residues which indicate their immaturity and reduced fertile potential, produce higher amount of ROS than normally shaped spermatozoa $[19,20]$.

The seminal plasma contains natural antioxidant, such as vitamins $\mathrm{C}$ and $\mathrm{E}$, superoxide dismutase (SOD), glutathione, uric acid, and the polyamine spermine that acts as a free radical scavenger [21]. However, the high concentration of unsaturated lipids in the plasma membrane and the relative paucity of oxyradical scavenger enzyme (due to the virtual absence of cytoplasma) make mature spermatozoa particularly susceptible to oxidative stress. Superoxide anion radical $\left(\mathrm{O}_{2}{ }^{-}\right)$is the main ROS produced by spermatozoa, which generates hydrogen peroxide spontaneously or following SOD activity. The pathways that contribute to ROS production are the NADPH oxidase system at level of cell plasma membrane and the NADH oxidoreductase at the mitochondria level [22].

Infections and/or inflammation of the urogenital tract may increase the number of seminal fluid leukocytes, and their activation results in a ROS overproduction. In fact, leukocytes, under physiological conditions, produce up to 1000 times more ROS than spermatozoa. This production plays an important role in the cellular defense mechanism against infections and inflammation but at the same time may damage spermatozoa. An increased number of leukocytes in the seminal plasma can also be present in varicocele, long sexual abstinence, or exposure to environmental factors [2328].

The polyunsaturated fatty acids of sperm plasma membrane are a target of ROS action leading to lipid peroxidation, measurable as malondialdehyde (MDA) in the seminal plasma, and loss of sperm motility [21]. ROS can also alter biofunctional sperm parameters, resulting in a greater number of spermatozoa with fragmented DNA that seems to be inversely correlated with sperm count, morphology, motility, and fertilization rate $[21,22]$. ROS overproduction causes also a greater frequency of single- and double-strand DNA breaks and increased DNA protein cross-linking [8]. Furthermore, ROS have the ability to damage mitochondrial DNA [21].

These findings support the administration of molecules with antioxidant activity in patients with oxidative stressinduced sperm damage. Antioxidants are widely available and relatively inexpensive when compared to other molecules used for fertility treatment. In addition, there is no evidence of adverse events and they seem to be effective in improving sperm parameters and in increasing a couple's chance of having a live birth [1].

\section{Antibiotic Treatment}

The choice of the antibiotic should be based on the nature of the microorganism identified and the results of the relative antibiogram, since a targeted therapy is recommended. Several classes of antibiotics may be used [29, 30]. We would also point out that most of these microorganisms may be sexually 
transmitted and it is necessary to stop sexual contacts for the time of treatment and also treat female partner to eradicate the infection when necessary.

4.1. Quinolones. Quinolones (ciprofloxacin, levofloxacin, ofloxacin, norfloxacin, pefloxacin, enoxacin, fleroxacin, lomefloxacin, and other new ones) have a favorable pharmacokinetic profile, with excellent oral bioavailability (greater than 95\%) for most. However, differences in peak serum concentrations and $\beta$-half-lives of elimination exist. As suggested by high apparent volumes of distribution and low binding to serum proteins, penetration into many body tissues and fluids is advantageous.

Oral bioavailability of quinolones has been shown to be in general good in sick as well as healthy subjects but is reduced by coadministration with magnesium- and aluminumcontaining acids, sucralfate (which contains aluminum), or ferrous sulfate [31]. Quinolones have an excellent ability to penetrate into the prostate and good activity against typical and atypical pathogens. They are associated with phototoxicity, CNS adverse events (variable among the different agents), and tendonitis.

Quinolones are considered a first-line therapy. Among the different quinolones, the most used in clinical practice are ciprofloxacin and levofloxacin. Ciprofloxacin is absorbed primarily on the duodenum and jejunum. Studies also suggest this drug is cleared by transepithelial elimination into the bowel lumen as well as by the renal route. Levofloxacin seems to offer advantages over ciprofloxacin for bacterial eradication rates and clinical improvement in patients with chronic prostatitis [32], whereas another study of similar size and design showed no significant differences between these two agents [11].

Dose and duration should be sufficient to eradicate the infection, for example, ciprofloxacin $500 \mathrm{mg}$ (once or twice/day) and levofloxacin $500 \mathrm{mg}$ (once/daily) for 20-28 days. The treatment may be split into two cycles of 10-14 days, separated by an interval of one-two weeks.

4.2. Trimethoprim. Trimethoprim is rapidly absorbed from the gastrointestinal tract, widely distributed into body tissues and fluids, including seminal fluid and prostatic tissue. It is eliminated by glomerular filtration and tubular secretion in urine; only small amounts are excreted in feces by biliary elimination. Trimethoprim is active against many relevant pathogens but has no activity against Pseudomonas, some enterococci, and some Enterobacteriaceae. Monitoring is unnecessary. It is a second-line therapy.

Dose and duration should be sufficient to eradicate the infection, for example, $200 \mathrm{mg}$ once or twice/day for 28 days. The treatment may be split into two cycles of 10-14 days, separated by an interval of one-two weeks.

4.3. Tetracyclines. Tetracyclines are readily absorbed and bound with plasma proteins, concentrated by the liver in the bile, and excreted in the urine and feces at high concentrations in a biologically active form. These drugs are contraindicated in renal and liver failure. They have good activity against Chlamydia trachomatis and Mycoplasma and lower efficacy against coagulase-negative staphylococci, Escherichia coli, other Enterobacteriaceae, and enterococci. There is no activity against Pseudomonas aeruginosa. They are associated with risk of skin sensitization. Tetracyclines are a second-line therapy. Dose and duration should be sufficient to eradicate the infection.

The Ureaplasma sp. isolates are susceptible to doxycycline and josamycin. Most studies report lower resistance rates for tetracyclines $(<5 \%)$.

Doxycycline is administered at the dose of $100 \mathrm{mg}$ once or twice/day for 28 days. The treatment may be split into two cycles of 10-14 days, separated by an interval of one-two weeks.

4.4. Macrolides. Macrolides have good penetration into the prostate and are active against Chlamydia trachomatis and Gram-positive bacteria but have an unreliable activity against Gram-negative bacteria. Macrolides are used for special indications, based on the microbiological findings. Minor side effects of macrolide administration include nausea, vomiting, diarrhea, and ringing or buzzing in the ears (tinnitus). Serious side effects, including allergic reaction and cholestatic hepatitis (inflammation and congestion of bile ducts in the liver), are generally associated only with the use of erythromycin.

Dose and duration should be sufficient to eradicate the infection. Azithromycin is prescribed at the dose of $1 \mathrm{~g}$ once/day for 7-10 days.

A number of studies have compared the microbiological eradication rate between the different antibiotics.

Higher eradication rates ( $>90 \%$ ) have been reported with azithromycin and levofloxacin either alone, in combination, or sequentially, depending upon the infection site (urethral, prostatic, or both) in patients with chronic bacterial prostatitis by Chlamydia trachomatis infection [33].

4.5. $\beta$-Lactam Antibiotics. $\beta$-lactam antibiotics (penicillin derivatives, cephalosporins, monobactams, and carbapenems) have a limited use in male infertility. Some of them can be used if a particular quinolone-resistant male urogenital infection is present, such as acute prostatitis caused by extended-spectrum $\beta$-lactamase-producing bacteria, which seems to be sensible to imipenem, cefoxitin, and amoxicillin/clavulanic acid [34].

Other uses include management of Neisseria gonorrhoeae infections whose prevalence has grown over the past decades. It is the second most commonly reported sexually transmitted bacterial infection in the United States, after Chlamydia trachomatis. The 2015 Centers for Disease Control and Prevention guidelines recommend dual therapy with intramuscular ceftriaxone and oral azithromycin as first-line treatment, although components of this type of treatment are met with a high level of resistance [35].

The recommended dose for uncomplicated gonococcal urethral infections is a single dose of ceftriaxone, $250 \mathrm{mg}$ intramuscularly, and either azithromycin (1 g orally) or doxycycline (100 mg orally twice/day) for seven days.

4.6. Antibiotics and Sperm Toxicity. Although the antibiotic treatment has been essential to preserve or restore normal 
sperm parameters in urogenital infections, some of them have spermotoxic effects. This side effect has not yet been directly shown in humans by randomized clinical trials, but there are data concerning testicular and/or sperm toxicity for some antibiotics in rats or mice. These include ciprofloxacin and pefloxacin [36], ofloxacin [37], lomefloxacin [38], tetracyclines [39], cefonicid and other cephalosporins [40], and norfloxacin in quails [41].

\section{Anti-Inflammatory Treatment}

\subsection{Nonsteroidal Anti-Inflammatory Drugs (NSAIDs)}

5.1.1. Salicylates. Salicylates include salicylates, diflunisal, and salsalate. There are no available data on the last two categories. The negative effect of mesalazine on fertility has been shown in patients with irritable bowel disease that at a certain point requires treatment cessation to achieve fertility. Indeed, the mean sperm concentration, sperm motility, percentage of spermatozoa with normal form, seminal fluid volume, and total motile sperm count increase after mesalazine discontinuation [42]. Another study showed a decrease of sperm count and motility in mice treated with sulfasalazine [43]. The administration of salicylate $(650 \mathrm{mg}$ four times a day) significantly decreased sperm motility after 3 days of treatment in four patients. The negative effect on sperm motility was not due to necrozoospermia [44].

5.1.2. Fenamic Acids. No data on fenamic acids are available on male fertility.

5.1.3. Profens. Few data are available on profens. A study showed that ibuprofen may cause a significant alteration of sperm parameters and chromatin/DNA integrity in mice. These deleterious effects are dose-dependent and are observed in early and late stages of drug administration [45]. On the other hand, another study showed that reproductive damage induced by continuous or intermittent hypoxia was partially ameliorated by the simultaneous treatment with ibuprofen [46].

5.1.4. Cox-2 Inhibitors (Coxibs). The data are contrasting for this class of NSAIDs. Studies on mice and turkeys showed a negative effect of coxibs on sperm parameters [47, 48]. In contrast, sperm parameters (but not morphology) improved in patients with chronic pelvic pain syndrome treated with a combination of $\alpha$-blockers and coxibs [49]. Similarly, sperm motility and morphology improved and seminal fluid leukocyte concentration decreased in patients with amicrobial leukocytospermia undergoing assisted reproductive technique treated with rofecoxib [50]. Similar data were reported in another study whose patients were given valdecoxib [9]. These findings suggest that coxibs may be prescribed in infertile patients with leukocytospermia. However, more data are needed to assess this indication.

The dose used in the clinical trials was of $25 \mathrm{mg}$ for rofecoxib, for a period of 30 days or $20 \mathrm{mg}$ once/day for valdecoxib for two weeks. This indication has been currently off-label for leukocytospermia in Italy.
5.1.5. Arylacetics. No recent data are available on the effects of arylacetics for male fertility.

5.1.6. Sulfonanilides. Sulfonanilides include the relatively COX-2 selective nimesulide. A study was conducted with nimesulide, in 30 cases of abacterial prostatovesiculitis and no specified infertility issue, showing that its oral administration at the dose of $100 \mathrm{mg}$ twice/day for three cycles of 10 days each reduced dysuric symptoms and improved inflammatory signs at transrectal prostate ultrasound evaluation. However, no statistically significant changes on sperm count and motility were observed, while a significant reduction in the number of abnormal forms occurred [51]. Another study showed that nimesulide does not seem to be spermatoxic in prepubertal rats at normal therapeutic doses [52].

5.1.7. Oxicams. No data are available on the effects of oxicams on male fertility.

Overall, NSAIDs should be considered for the treatment of the acute forms of male accessory gland inflammation for symptoms relief and they should be avoided for chronic usage (if possible) in patients with infertility. Additional studies are needed to explore the possibility of positive effects of coxibs on patients with "idiopathic" leukocytospermia.

5.2. Steroidal Anti-Inflammatory Drugs. Glucocorticoids are employed for the treatment of infertility when antisperm antibodies (ASA) are demonstrated. Recent studies have investigated the effects of ASA and the correlation between ASA and sperm parameter abnormalities, but inconsistent results have been reported. A recent meta-analysis shows a significant negative effect of ASA on sperm concentration and total sperm motility (progressive + nonprogressive) which are lower in ASA positive patients than in ASA negative and sperm liquefaction which has been longer in ASA positive patients [53]. In addition, an immune-suppressive treatment has been found poorly effective and many other treatments have been proposed such as ART (intrauterine insemination and in vitro fertilization) and laboratory techniques (sperm washing, immunomagnetic sperm separation, proteolytic enzyme treatment, and use of immunobeads) [54].

\section{Fibrinolytic Treatment}

In this section, we discuss three of the main fibrinolytic agents evaluated in literature and widely used clinical practice: serratiopeptidase, bromelain, and escin.

6.1. Serratiopeptidase. Serratiopeptidase is a proteolytic enzyme of 45,000-60,000 kD molecular weight and particularly a metalloprotease containing a zinc atom which plays a pivotal role for its proteolytic activity [55]. It derives from nonpathogenic enterobacteria belonging to Serratia species E-15. This microorganism was originally isolated during late 1960s from the intestines of silkworm Bombyx mori, its natural habitat. The enzyme facilitates the emerging moth to dissolve its cocoon. Serratiopeptidase is produced by purification from culture of Serratia E-15 bacteria [56]. 
In rats, orally administered serratiopeptidase is absorbed from the intestinal tract and reaches the circulation in an enzymatically active form $[57,58]$. However, pharmacokinetic data including its oral bioavailability and the minimal concentration required for its therapeutic action are not reported in humans.

Serratiopeptidase seems to act as analgesic, anti-inflammatory, and fibrinolytic/caseinolytic [59-61]. As for the antiinflammatory property, this enzyme reduces swelling by decreasing the amount of fluid in the tissues, thinning the fluid, and facilitating fluid drainage. In addition, its enzyme activity dissolves dead tissue surrounding the injured area so that healing is accelerated. It acts also by modifying cellsurface adhesion molecules that guide inflammatory cells to site of inflammation. Its fibrinolytic/caseinolytic activity relates on the breaking down of fibrin and other dead or damaged tissues without harming the healthy tissue. This could enable the dissolution of blood clots, atherosclerotic plaques, and facilitating antibiotic penetration. Two animal and eight clinical studies support its use as anti-inflammatory agent but larger, better-designed, placebo-controlled trials are needed to clearly prove its efficacy. In addition, data on tolerability and long-term safety of this enzyme lack [62].

A clinical study showed a small significant increase in sperm count compared to pretreatment value, after treatment with levofloxacin plus serratiopeptidase, in patients with $>2$ years infertility and male accessory gland infection/inflammation, while sperm motility and morphology did not change [63]. It is possible that the enzyme could enhance the penetration of antibiotics in the infected tissue and increase the activity of quinolones against the development of bacterial biofilms [64].

There are not many published articles on the adverse drug reactions (ADRs) to serratiopeptidase. The only information may be obtained from drug company monographs. The ADRs include allergic skin reaction that ranges from dermatitis to extreme cases of Stevens-Johnson syndrome or erythema multiforme, muscle aches and joint pains, gastric disturbances like anorexia, nausea, and abdominal upset, cough rarely pneumonitis [65], and coagulation abnormalities. It has to be taken on an empty stomach or at least two hours after eating, and no food should be consumed for about 30 minutes after the ingestion of serratiopeptidase.

The recommended dose of serratiopeptidase for specific indications, in particular, has been not mentioned anywhere; however, serratiopeptidase-based drugs commonly range from 30000 to $60000 \mathrm{UI} /$ day.

6.2. Bromelain. Bromelain has been studied since 1875 and it is used as a phytomedical compound [66]. Bromelain is a mixture of different thiol endopeptidases and other components like phosphatases, glucosidase, peroxidases, cellulases, glycoproteins, carbohydrates, and several protease inhibitors [67]. Bromelain seems to exert a wide range of therapeutic benefits; it is known to enhance absorption of drugs, particularly antibiotics [68, 69]. Bromelain acts on fibrinogen giving products that are similar, at least in its effect, to those formed by plasmin [70]. Experiment in mice showed that antacids such as sodium bicarbonate preserve the proteolytic activity of bromelain in the gastrointestinal tract [71]. Bromelain is absorbed by the human intestine without degradation and loss of its biological activity [72, 73]. The body can absorb significant amount of bromelain; about $12 \mathrm{~g} /$ day of bromelain can be consumed without any major side effects.

Clinical studies have shown that bromelain may be useful for the treatment of several disorders (cardiovascular diseases, osteoarthritis, immunogenicity, blood coagulation, fibrinolysis, diarrhea, effects on cancer cells, and debridement burns) [74]. No data are however available on the role of bromelain given alone on male fertility. However, many studies suggest an effect of bromelain on antibiotic potentiation; combined bromelain and antibiotic therapy has been shown more effective than antibiotic alone in eradication of various infections, including urinary tract infection [75].

Bromelain has been used in therapeutic schemes ranging from $160 \mathrm{mg}$ per day to $750-1000 \mathrm{mg} /$ day. The best results occurred when it was administered four times a day and the effectiveness was dose-dependent [76]. Bromelain has very low toxicity [77]. In human clinical tests, side effects were generally not observed; however, a report indicated that individuals with preexisting hypertension might experience tachycardia following high doses of bromelain [78]. Moreover, bromelain can cause IgE-mediated respiratory allergies of both the immediate type and the late phase of immediate type [79].

6.3. Escin. Escin is a natural mixture of triterpene saponins extracted from the seeds of Aesculus chinensis Bgem or Aesculus wilsonii Rehd, which mainly consist of A, B, C and D escin. Experimental evidence suggests that escin exerts antiinflammatory and antiedematous effects. At present, escin injection has been widely used clinically to prevent inflammatory edema after trauma such as fracture and surgery in China $[80,81]$. Few studies have analyzed a possible role of escin in male fertility. A Chinese study, evaluating the role of escin in varicocele-associated infertility, showed that a daily oral dose of $60 \mathrm{mg}$ ( $30 \mathrm{mg}$ every $12 \mathrm{~h}$ ) for 2 months improved sperm concentration and caused changes in the diameter of the spermatic vein [82]. This dose is higher than the dose used for the venous insufficiency of other districts (orally: $40 \mathrm{mg}$ daily; or intravenously: 5-10 mg daily). Treatment duration is not well established, although medium- and long-term administration do not influence general tolerance.

Escin causes mild adverse effects with very low frequencies, most of which can be reduced or avoided without the need to administer symptomatic drug after advising the patients to take escin after meal. The most important adverse effects occur when escin is administered parentally. The most common reactions are phlebitis and allergic reactions; phlebitis occurring at the first day after intravenous medication accounts for $70 \%$ and can cause physical and psychological pain, which directly affects its clinical use. Escin has little effect on vital signs, blood counts, liver, or kidney function. 
TABLE 1

\begin{tabular}{lcr}
\hline Antibiotic & Eradication rate & References \\
\hline Ciprofloxacin & $40-77 \%$ & {$[11,12]$} \\
Levofloxacin & $75 \%$ & {$[11]$} \\
Azithromycin & $80 \%$ & {$[12-14]$} \\
Doxycycline & $77 \%$ & {$[14]$} \\
Clarithromycin & $80 \%$ & {$[13]$} \\
Azithromycin + ciprofloxacin & $62-77 \%$ & {$[4]$} \\
\hline
\end{tabular}

\section{Antioxidants}

The protective antioxidant system comprehends enzymatic factors (superoxide dismutase (SOD), catalase and glutathione peroxidase (GPX), nonenzymatic factors and low molecular weight compounds (glutathione, N-acetylcysteine (NAC), vitamins A, E, and C, coenzyme Q10 (CoQ10), carnitines, myoinositol (MYO), lycopene, astaxanthin, Serenoa repens, etc.), and micronutrients (selenium, zinc, and copper)) which interact each other to ensure an optimal protection against the oxidative stress. A deficiency of one of them may result in a decrease of total plasma antioxidant capacity [23]. The main antioxidants are discussed below whereas others are shown in Table 1.

7.1. Superoxide Dismutases. SODs are metalloenzymes that convert superoxide to hydrogen peroxide $\left(\mathrm{H}_{2} \mathrm{O}_{2}\right)$ and comprehend two intracellular and one extracellular forms. The intracellular form contains copper and zinc in the active center (CuZnSOD). It is encoded by the SOD1 gene and it is mainly localized in the cytoplasm. The other intracellular form is manganese SOD (MnSOD) that acts in the mitochondrial matrix [23]. Its gene, $S O D 2$, is inducible under various inflammatory conditions and the nuclear factor kappa B (NF-kB) appears to be the main factor responsible for its induction. Homozygous SOD2 gene-deficient mice have severe cardiovascular damage and die soon after birth. No abnormality in the genital tract has been reported in these mice. On the contrary, transgenic male mice that express higher levels of MnSOD are infertile. Since SOD only dismutates superoxide anion into hydrogen peroxide, the resulting $\mathrm{H}_{2} \mathrm{O}_{2}$ may also cause a toxic effect in testicular cells [83].

The extracellular form of SOD (ECSOD), encoded from SOD3 gene, can be present in a free form or can be connected to the surface polysaccharides. It is structurally similar to the MnSOD, but it has zinc and copper in the active center. It has been shown that erectile function is improved by transferring the SOD3 gene to the penis in aged rats. Scavenging superoxide increases nitric oxide (NO) half-life that results in increased cGMP levels [83].

The main active isoenzymes in the seminal plasma are CuZnSOD (75\%) and ECSOD (25\%) which probably originate from the prostate [84]. SODs have been observed to play a role in the protection of testicular cells against heat stress-induced apoptosis both in vivo and in vitro $[85,86]$. Moreover, SOD activity has been lower in infertile patients than in fertile controls and correlates positively with sperm motility and morphology [87].

Some in vitro studies suggest that SODs may play a role in improving sperm parameters in thawed semen samples. In fact, supplementation with manganese (III) mesotetrakis (N-ethylpyridinium-2-yl)porphyrin chloride (MnTE), a permeable SOD mimetic agent, seems to improve total motility, membrane integrity, and viability of goat semen samples after thawing, the acrosomal integrity and the blastocyst formation rate [88]. However, since MnTE supplementation protects spermatozoa from superoxide but not from $\mathrm{H}_{2} \mathrm{O}_{2}$, the degree of sperm parameters improvement is higher when also catalase is simultaneously added [89]. There are evidences for positive effects of the treatment with SODs also on human spermatozoa. In fact, the supplementation of exogenous SODs at the dose of $400 \mathrm{U} / \mathrm{mL}$ to the human sperm suspension prevented the loss of motility and the increase of MDA concentration, thus showing a significant role of SODs for human sperm motility [90]. Actually, SOD is included in some over-the-counter products that contain also other anti-antioxidants (e.g., D-chiro-inositol, zinc, and folic acid), recommended for the treatment of male infertility. There is a lack of studies investigating the effects of SOD oral supplementation on human sperm. Hence, there is not agreement about the dosage. However, the most common therapeutic scheme suggested consists of an oral dosage of 150 UI a day for at least three months.

7.2. Catalase. Catalase is a heme enzyme with a centrally located iron atom. It catalyzes the decomposition of $\mathrm{H}_{2} \mathrm{O}_{2}$ into molecular oxygen $\left(\mathrm{O}_{2}\right)$ and water $\left(\mathrm{H}_{2} \mathrm{O}\right)$. Its presence has been shown in the seminal plasma and spermatozoa of both humans and rats. The extracellular enzyme is produced by the prostate.

Under physiological conditions, catalase plays a role in the nitric oxide-induced sperm capacitation [23]. Its activity has been associated with low sperm quality [91, 92]. In fact, $\mathrm{H}_{2} \mathrm{O}_{2}$, which increases in case of catalase deficiency or reduced activity, plays a substantial role on sperm motility due to the decrease in membrane fluidity that is important for sperm-oocyte fusion [93]. It is not commercially available.

7.3. Glutathione Peroxidase. GPXs reduce hydrogen peroxide and organic peroxides, including phospholipids, using the reduced form of glutathione $(\mathrm{GSH})$ as an electron donor [94]. GPXs protect sperm DNA from oxidative damage, playing a role in the chromatin condensation and mainly in 
the mitochondrial matrix [23]. GPX-defective expression in human spermatozoa has been reported to be associated with OAT $[95,96]$.

GPXs are divided into two groups according to the presence of selenocysteine in the enzyme isoform. Since selenium deficiency has been associated with male infertility, selenium-containing GPXs are suspected to be a candidate for the defective molecule. At least four isoenzymes belong to the selenium-containing GPX in mammals.

GPX1 is a cytosolic isoform, widely distributed in tissues and, like other antioxidant enzymes, and prevents apoptosis induced by oxidative stress and other stimuli. GPX1 knockout mice do not show reproductive abnormalities.

GPX2 and GPX3 are gastrointestinal and plasma isoforms, respectively.

GPX4 is highly expressed in testis and represents about the $50 \%$ of the capsule material, which embeds the helix of mitochondria in the midpiece of spermatozoa. GPX4 gene knockout mice show premature embryonal death. The GPX4 gene encodes also for a protein that has a high sequence identity to GPX4 except for the N-terminal region. This protein is specifically present in sperm nuclei and is considered to act as protamine thiol peroxidase.

GPX5 is a nonselenium enzyme. It is exclusively expressed in the epididymis and secreted in the caput and caudal epididymal lumen. It represents the $6 \%$ of the secretory epididymal proteins. However, the activity of nonselenium dependent GPX in low and, hence, its contribution as a GSHdependent peroxide scavenger is ambiguous [83].

However, neither catalase nor GPXs are currently used for the treatment of male infertility.

7.4. Glutathione. Glutathione is a sulfur-containing tripeptide present in both a reduced (GSH) and an oxidative (GSSG) states. GSH participates in preserving the intracellular milieu in a reduced state and, in addition, it is an electron donator to GPX. GSH displays its antioxidant activity by the reconstruction of thiol groups (-SH) in proteins and preventing cell membrane from lipid oxidation [23].

GSH levels are maintained through two metabolic pathways: one is the de novo synthesis from Cys, Glu, and Gly that is catalyzed by the $\gamma$-glutamylcysteine synthetase ( $\gamma$ GCS) and glutathione synthetase; the other is its recycling by glutathione reductase, using NADPH as an electron donor. Glutathione is pumped out when it is oxidized or forms conjugates with cytotoxic compounds, including xenobiotical chemicals. Plasma glutathione is hydrolyzed $\gamma$-glutamyl transpeptidase (GGT), localized at the cellular surface as a membrane protein, into its consisting amino acids that are then taken up by the specific transporter and reused by cells [83].

In animals, GSH therapy affects positively sperm quality. It has a crucial role in increasing sperm motility and fertilization in bulls with asthenozoospermia due to varicocele and in rabbits with dispermy caused by cryptorchidism [97].

Glutathione reduction in human seminal plasma leads to instability of the midpiece of the spermatozoa, resulting in a motility disorder [98]. Some authors suggested that its supplementation plays a therapeutic role in some andrological diseases, particularly during inflammation. Accordingly, its supplementation in infertile men with unilateral varicocele or inflammation of the urogenital tract (two conditions in which radical oxygen species or another toxic compound production plays a pathogenetic function) leads to a significant improvement of sperm parameters, such as concentration, motility, and morphology [99]. These effects on spermatozoa can be partially reversed in case of not too severe structural cell membrane damage [98], a prominent protective role of GSH on the lipid components of the cell membrane [21].

Glutathione is given at the dosage of $600 \mathrm{mg} /$ day intramuscularly for 2-3 months. Hence, glutathione is seldom prescribed for male infertility. However, because of the route of administration, the compliance is low and, currently, GSH is hardly used for the treatment of male infertility.

7.5. N-Acetyl-Cysteine (NAC). NAC is a glutathione precursor. NAC is effective in metal chelation and it seems to improve sperm motility and to prevent sperm DNA oxidative damage [23]. In an animal model, it is able to improve sperm parameters and seminal vesicles weight, previously altered by treatment with $\mathrm{As}_{2} \mathrm{O}_{3}$ [100]. Furthermore, it significantly improves seminal fluid volume and viscosity and increase sperm motility in humans [101]. In women suffering from polycystic ovary syndrome, NAC (administered at the doses of $1500 \mathrm{mg} /$ day) has been shown to ameliorate oocyte and embryo quality, representing an alternative to metformin prescription [102]. Such findings support the therapeutic use of this compound for the treatment of human infertility.

The most common oral dosage used is $600 \mathrm{mg} /$ day. NAC is commercialized in combination with other antioxidants. Its administration is suggested for at least three months.

7.6. Vitamin A. Carotenoids are a group of fat-soluble organic compounds found mainly in yellow, red, orange, and pink vegetables. These retinoids are precursor of vitamin A. Retinal is formed from them in the gastrointestinal tract, before being converted to retinol, the most important component of vitamin A.

Carotenoids are natural antioxidants that protect cell membrane integrity, regulate epithelial cell proliferation, and are involved in the regulation of spermatogenesis [23]. Moreover, in rats retinoids have various effects on fetal and neonatal Sertoli, germ, and Leydig cell [103]. Carotenoid deficiency in the diet can lead to a reduction in sperm motility [23]. Studies conducted on bulls have shown that retinol might stabilize sperm acrosomal membrane when oxidative stress increases because of the high temperature [104]. In humans, lower serum retinol concentration has been correlated to a worse sperm quality [105]. Hence, vitamin A administration could be a therapeutic choice for the treatment of human male infertility. Not many studies have evaluated the effects of vitamin A on human sperm parameters. Currently, it is seldom added to the over-the-counter preparation for male infertility treatment. However it should be strengthening the concept that vitamin A has been shown to be toxic and may be teratogenic in higher dose $[106,107]$. 
7.7. Vitamin C (Ascorbic Acid). Vitamin C has a 10 -fold higher concentration in seminal plasma than in the serum [108]. It has a more powerful antioxidant action when peroxyradicals are present in the aqueous phase [109] than in the lipid membrane [110]. In mice, at a concentration equivalent to the human therapeutic dose $(10 \mathrm{mg} / \mathrm{Kg})$, it is able to reduce MDA concentration, increasing sperm count and the proportion of normal sperm population [111].

In humans, the seminal acid ascorbic levels correlate positively with the percentage of morphologically normal spermatozoa [112] and negatively with DNA fragmentation index [113]. This finding supports the therapeutic use of vitamin $C$ in infertile males. At concentrations lower than $1000 \mu \mathrm{mol} / \mathrm{L}$, vitamin $\mathrm{C}$ is an antioxidant; at higher concentrations it acts as a prooxidant agent $[22,114]$. The dose of $1 \mathrm{~g} /$ day provides a 2.2 -fold increase in plasma acid ascorbic concentrations [115]. The majority of the studies reported in literature investigating the effect of vitamin $\mathrm{C}$ administration on sperm quality refer to this orally administered dosage $[116,117]$. Accordingly, $1 \mathrm{~g}$ daily vitamin C treatment improves human quality, increasing mean sperm count, concentration, and motility [118]. The duration of the treatment is not well established. There is evidence for sperm parameters amelioration after one month of treatment [117], but longer period of treatment is also reported [116]. The dose of vitamin $\mathrm{C}$ must, however, is not excessive because high doses may act as a prooxidant, particularly in persons with the haptoglobin type 2- 2 [106, 107].

7.8. Vitamin E. Vitamin E ( $\alpha$-tocopherol) is a fat-soluble organic compound mainly localized in cell membranes. It protects sperm cell membrane form oxidative stress-induced damage, preventing lipid peroxidation and capturing free hydroxyl radicals and superoxide [23]. Efforts have been made to establish if sperm parameters could be improved by vitamin E supplementation [119]. Its seminal plasma concentration significantly increases when it is administered at doses of 300 and $1200 \mathrm{mg} /$ day for three weeks [120]. The $\alpha$-tocopherol concentration in spermatozoa is independent from the total $\alpha$-tocopherol concentration in seminal plasma, and it significantly correlates with the percentage of motile spermatozoa [121]. A double-blind placebo-controlled trial showed an improved sperm function in vitro after $600 \mathrm{mg}$ daily administration of vitamin $\mathrm{E}$ for three months. The administration resulted in improved sperm motility and ability to bind the hamster oocyte in the hamster egg penetration test [119]. In other studies, lower doses (200 or $300 \mathrm{mg} /$ day) have been used [122-124].

A placebo-controlled double-blind study reported an improvement of sperm motility in men with oligoasthenoteratozoospermia after vitamin E oral supplementation. The enhancement of sperm motility was associated with a decreased sperm production of MDA, the end product of the lipid peroxidation [125]. Furthermore, in the course of the six-month treatment period, $21 \%$ of patients belonging to the treated group achieved pregnancy [125]. Seminal plasma MDA decrease seems to correlate with the percentage of successful attempts to achieve pregnancy. In a prospective study, 15 normozoospermic men with low fertilization rates in their earlier ART cycles were treated with $200 \mathrm{mg} /$ day of vitamin $\mathrm{E}$ for three months. The high MDA concentration declined to normal rate and the fertilization rate per cycle significantly improved after one month of treatment [124]. Finally, dietary habits seem also to play a role in semen quality, since a positive correlation has been found between vitamin $\mathrm{E}$ dietary intake and progressive and total motility [118]. This evidence suggests that vitamin $\mathrm{E}$ may have a positive effect on semen quality, enhancing the pregnancy rate. Altogether, these findings suggest that vitamin $\mathrm{E}$ could be a therapeutic choice for the treatment of male infertility. However, we would emphasize that, besides their interesting antioxidant properties, vitamin $\mathrm{E}$ analogs, especially tocopheryl succinate, can exert adverse effects on gap junctional intercellular communication, which could explain their controversial effects in spermatogenesis $[106,107]$.

7.9. Coenzyme $Q_{10}$. $\mathrm{CoQ}_{10}$ is the only lipid soluble antioxidant synthetized endogenously. In the Q-cycle it is present in three redox states: ubiquinone $\left(\mathrm{CoQ}_{10}\right.$-oxidized $)$, ubiquinol ( $\mathrm{CoQ}_{10} \mathrm{H}_{2}$-reduced), and semiquinone (partially reduced, as radical). The reduced form has a higher antioxidant effect and concentration in the body is approximately $90 \%$ of total $\mathrm{CoQ}_{10}$. It inhibits protein and DNA oxidation and lipid peroxidation. $\mathrm{CoQ}_{10}$ regulates the mitochondrial electron transport in the respiratory chain, receiving electrons from complex I and complex II and passing them to complex III, and it transfers protons from fatty acids to the matrix. It also regulates the permeability transition pore opening and nutrition uptake through the voltage dependent anion channel (VDAC) of the outer mitochondrial membrane [126].

A number of clinical studies documented the beneficial effects of ubiquinone on male fertility. In fact, it has been shown to improve sperm parameters (concentration, motility, and morphology) in men with idiopathic OAT $[127,128]$, with positive effects on the pregnancy rate [129]. It displays a protective effect against oxidative stress and sperm DNA damage. In addition, $\mathrm{CoQ}_{10}$ treatment improves sperm parameters and antioxidant status in infertile men with varicocele [126]. Different therapeutic schemes are reported in literature. The lower dosage used is $90 \mathrm{mg} /$ day for a minimum of 3 months to a maximum of 9 months, but positive effects on sperm parameters have been obtained also by higher dosages (e.g., $100 \mathrm{mg}$ /day for three menses, $200 \mathrm{mg}$ for six months, etc.). The highest dosage reported is $300 \mathrm{mg}$ twice a day for twelve months [126].

Ubiquinol has a stronger antioxidant action in comparison with ubiquinone. It can regenerate other antioxidants such as vitamin $\mathrm{E}$ and vitamin $\mathrm{C}$. In addition, $\mathrm{CoQ}_{10}$ testicular biosynthesis is very active and high levels of ubiquinol are present in sperm [130]. Ubiquinol sperm concentration strongly correlates with sperm count, motility, and morphology. In addition, $\mathrm{Q}_{10}$-total concentration directly correlates with sperm motility [126]. Ubiquinol is administered orally at a dosage of 150 to $200 \mathrm{mg}$ daily, for at least four months.

Carnitine-ubiquinol combination displays a beneficial effect on sperm mitochondrial function of infertile men. It may be due to their uptake by VDAC of the outer mitochondrial membrane, along with the activity of carnitine 
palmitoyltransferase I (CPTI) in outer mitochondrial membrane. However, further studies are required to support this hypothesis [126].

7.10. Carnitine. Currently, carnitine is the molecule with antioxidant activity that has the greatest consensus in literature, especially in its forms L-carnitine and L-acetylcarnitine.

L-carnitine (mainly of exogenous origin though human beings are able to synthesize) is a high-polar, water-soluble quaternary amine. It acts as an essential cofactor for the transport of long chain fatty acids within the mitochondrial matrix in order to facilitate the oxidative processes and to enhance cellular energy production [131, 132]. Lacetylcarnitine, instead, is formed by the enzyme acetyl-Lcarnitine transferase that modulates the intracellular and mitochondrial concentration of coenzyme $\mathrm{A}(\mathrm{CoA})$ and acetyl-CoA $[10,133]$. Interestingly, high concentrations of carnitine are present in the male reproductive tract and particularly in the epididymis, suggesting its crucial role in energy metabolism and sperm maturation [10, 133]. Hence, carnitine concentration in the ejaculate is considered a marker of epididymal function and some studies have shown a decreased L-carnitine concentration in the seminal fluid of patients with epididymitis $[134,135]$.

The antioxidant properties of carnitine have been studied in men with male accessory gland inflammation. As previously said, inflammatory processes increase ROS production from leukocytes and/or spermatozoa with a consequent increased oxidative stress. Since prostatovesiculoepididymitis (PVE) is the diagnostic category with a higher level of oxidative stress, some studies have evaluated the antioxidant properties of L-carnitine administration in patients with microbial PVE. The results of these studies have shown that the best effect is obtained administering first antibiotic and anti-inflammatory drug and subsequently L-carnitine. The coadministration of antimicrobial agents and antioxidants is less effective while treatment with L-carnitine alone has no effect $[10,136]$.

The beneficial effects of L-carnitine on sperm parameters are well known. The data in the literature show a statistically significant improvement of sperm progressive motility in patients with OAT treated with L-carnitine or acetyl-Lcarnitine at the dose of $3 \mathrm{~g} / \mathrm{day}$ [137-139] for some months. Moreover, treatment with acetyl-L-carnitine increases sperm motility and viability in asymptomatic infertile patients with ROS overproduction and ultrasonographic evidence of PVE who already received antimicrobial therapy [140]. However, despite improving sperm parameters, there is no evidence of statistical significant variation of seminal plasma $\alpha$-glycosidase concentration (a marker of epididymal function) and of sperm membrane lipid peroxidation [141]. Combination therapy with L-carnitine ( $2 \mathrm{~g} /$ day) and acetyl-Lcarnitine (500 $\mathrm{mg}$ twice a day) is also effective in improving sperm quality in infertile patients [142] and it improves the total oxyradical scavenging capacity of the seminal fluid [143] and sperm parameters [144]. Interestingly, the addition of L-carnitine in samples to be cryopreservation improves significantly sperm quality [145].
In conclusion, the administration of carnitines is a rational and effective therapeutic strategy for the treatment of male infertility, since it leads to an improvement in sperm parameters. The best therapeutic scheme is represented by the coadministration of at least $2 \mathrm{~g} /$ daily of L-carnitine and at least $1 \mathrm{~g} /$ daily of acetyl-L-carnitine for at least three months.

7.11. Myoinositol. Inositol is a component of the vitamin B complex. MYO, the most biologically important form in nature, is a precursor of second messengers and it is involved in several signal transduction mechanisms in the cell membrane. It regulates seminal plasma osmolarity, the expression of proteins essential for embryogenetic development and for sperm chemiotaxis and sperm motility. In addition, inositols are involved in sperm capacitation and acrosome reaction.

Incubation with MYO results in an increased sperm motility and in a higher number of spermatozoa retrieved by swim-up in both normozoospermic men and in patients with abnormal sperm parameters. This was associated with an improvement of sperm mitochondrial function in patients with OAT $[146,147]$. On this basis, the therapeutic use of MYO has been suggested in both in vivo and in vitro assisted reproductive techniques. Accordingly, oral supplementation with MYO seems to improve sperm parameters $[146,148$, 149]. In particular, a double-blind, randomized, placebocontrolled study showed that patients with idiopathic infertility, treated for three months with MYO (2g twice daily), had a significant increase of sperm concentration, total count, progressive motility, and acrosome-reacted spermatozoa. In addition, MYO rebalances $\mathrm{LH}, \mathrm{FSH}$, and inhibin-B concentrations [148].

The most frequently reported supplementation strategy consists of a daily oral dose of $4 \mathrm{~g}$ (plus $400 \mu \mathrm{g}$ of folic acid), for at least two months.

7.12. Lycopene. Lycopene is a constituent of the human redox protection mechanism against ROS. Although few studies investigated its effects on sperm parameters, it seems to be a therapeutic choice in the treatment of idiopathic male infertility. In facts, its oral administration $(2 \mathrm{~g}$ twice a day for 3 months) improved sperm concentration and motility [150]. Furthermore, lycopene displays a protective effect against cryopreservation injury of postthawing human spermatozoa. In fact, the addition of lycopene at a proper concentration to cryoprotectant reduces oxidative damage to sperm mitochondria in the freezing-thawing process, attenuates oxidative stress injury induced by ROS to sperm plasma membrane, and improves the antiapoptosis sperm ability [151]. Various lycopene supplementation studies conducted on both humans and animals have shown promising results in alleviating male infertility by decreasing lipid peroxidation and DNA damage and increasing sperm count and viability. Improvement of these parameters indicates a reduction of the oxidative stress, and thus spermatozoa were less vulnerable to oxidative damage, which increases the chances of a normal sperm fertilizing the egg. Human trials have reported sperm parameter improvement and pregnancy rates with supplementation of 4-8 mg of lycopene daily for 3-12 months. However, further detailed and extensive research is 
still required to determine the dosage and the usefulness of lycopene for male infertility treatment [152].

7.13. Astaxanthin. Astaxanthin is natural occurring xanthophyll. Only one study described its effects on human male fertility. A supplementation with $16 \mathrm{mg}$ daily of astaxanthin in 30 infertile patients resulted in higher sperm linear velocity, better capacity of binding the oocyte in the hamster penetration test, and higher total and per cycle pregnancy rates compared to the placebo group [153]. In a model of obese rats, vitamins $\mathrm{A}$ and $\mathrm{E}$ and astaxanthin administration was associated with better viability, motility, and morphology of spermatozoa obtained from the tail of the epididymis and with a significantly higher number of spermatogonium and Sertoli cells at the histological evaluation [154]. This finding led to the hypothesis that low sperm quality of obese men may be improved by the administration of this cocktail of antioxidants. However, other studies on a greater number of patients are needed to confirm if human sperm parameters may benefit from astaxanthin administration. Astaxanthin is administered in combined therapies at a daily dose of $16 \mathrm{mg}$. The duration of the treatment is not defined; in the mentioned study, astaxanthin was administered for three months [153].

7.14. Serenoa repens. Serenoa repens (saw palmetto) is a natural product with anti-inflammatory properties, derived from the American dwarf palm [155]. Currently, it is used to treat inflammatory symptoms in patients with benign prostatic hyperplasia and chronic prostatic inflammation [156]. Up to now, only a few and old studies have investigated its effects on sperm parameters. According to Ondrizek and colleagues, high concentration of Serenoa repens, Echinacea, or ginkgo inhibits human sperm motility $[157,158]$. Moreover, Serenoa repens does not have any effect on oocyte penetration and sperm DNA integrity, while other herbs (such as Echinacea purpurea, Ginkgo biloba, and Hypericum perforatum) damage these parameters $[157,158]$. On this basis, Serenoa repens does not seem to ameliorate sperm parameters. Further studies are needed to confirm this conclusion.

7.15. Micronutrients. The concentration of micronutrient such as selenium, zinc, and copper correlates with human sperm quality [23].

7.15.1. Selenium. Selenium is a micronutrient essential for normal testicular development, spermatogenesis, sperm motility, and function. The lack of selenium has been correlated to seminiferous epithelium atrophy, disorders of spermatogenesis, maturation of spermatozoa in the epididymis, testis volume reduction, decreased sperm motility, and altered sperm morphology (mainly in the head and in the midpiece) $[23,159]$. The exact mechanism by which selenium reduces oxidative stress and improves sperm parameters is still controversial. Its action seems to be mediated by selenoenzymes, such as GPXs [160].

Selenium is given orally at a dosage that ranges from $80 \mu \mathrm{g}$ to $300 \mu \mathrm{g}$ once a day, alone or in combination with antioxidants, for at least three months.
7.15.2. Zinc. Zinc is a component of over 200 enzymes involved in the biosynthesis of nuclear acids, proteins, and the process of cell division [23]. It has been reported to normalize oxidosensitive indices and catalase-like activity in the seminal fluid of asthenozoospermic patients [161].

Zinc is given orally at the dose of $220 \mathrm{mg}$ once or twice a day for three to four months, alone or in addition to folic acid (5 mg daily). In combined therapies, it is administered at the dose of at least $10 \mathrm{mg}$ a day. It should be given in the esterified formulation as zinc picolinate that is best taken up by the intestinal tract $[106,107]$.

7.15.3. Copper. Copper is a trace element whose seminal plasma concentration correlates with sperm quality [23]. A few studies report a positive effect of copper supplementation on sperm parameters in animals. In vitro supplementation with copper on ejaculated buffalo sperm led to a better protection through the process of dilution, equilibration, and freeze-thawing at the dose of $32 \mu \mathrm{g} / \mathrm{L}$ compared to the dosage of $64 \mu \mathrm{g} / \mathrm{L}$ [162]. In addition, dietary copper supplementation at a dosage of $110 \mathrm{mg} / \mathrm{kg}$ has been shown to prevent the adverse effects produced by $12 \mathrm{mg} / \mathrm{kg} /$ day of tetrathiomolybdate in rat spermatozoa [163]. No studies have explored the effects of copper supplementation on human sperm parameters. Copper is not prescribed for the treatment of male infertility.

7.15.4. Combined Therapies. The synergic effect of some component with different antioxidant properties has been studied. In a randomized trial, the daily administration of vitamin E (400 mg) and selenium (225 $\mu \mathrm{g}$ ) for three months resulted in a significant decrease in MDA concentrations and an improvement of sperm motility [93]. In mice, the coadministration of vitamin C $(10 \mathrm{mg} / \mathrm{kg})$ and vitamin $\mathrm{E}(100 \mathrm{mg} / \mathrm{kg})$ led to a decrease of testicular MDA content, along with increased sperm count and decreased percentage of spermatozoa with abnormal form [111]. According to Greco and colleagues, the daily administration of vitamin C ( $1 \mathrm{~g})$ and vitamin E (1 g) for two months significantly decreased the percentage of human DNA-fragmented spermatozoa $[164,165]$. In addition, this association led to an improvement in the clinical pregnancy and implantation rates compared to the group of patients receiving placebo $[164,165]$. Furthermore, there is evidence for an increase of seminal vitamin $\mathrm{E}$ concentration and of its oxidative stability after cryopreservation if high amount of dietary $\alpha$-tocopheryl acetate is consumed. A decrease of seminal plasma ascorbate concentration is associated with a decreased fertilization rate. In rabbits, a high amount of dietary vitamin E (50 versus $200 \mathrm{mg} / \mathrm{kg}$ diet) significantly increased the level of vitamin $\mathrm{E}$ in the seminal fluid and the sperm oxidative stability after storage at $5^{\circ} \mathrm{C}$ for $24 \mathrm{~h}$.

Ascorbic acid showed a different effect in relation to the vitamin E status of animals: when associated with the higher level of vitamin $\mathrm{E}$ it increased vitamin $\mathrm{E}$ and the semen oxidative stability, whereas both parameters were reduced with lower vitamin E levels. Hence, their combination significantly improves the viability and kinetics of spermatozoa with an increased fertility rate [166]. These evidences sustain 
TABLE 2: List of all available treatments.

\begin{tabular}{lc}
\hline Antibiotics & Quinolones, trimethoprim, tetracyclines, macrolides, $\beta$-lactam antibiotics \\
\hline NSAIDs & Salicylates, profens, sulfonanilides \\
\hline $\begin{array}{l}\text { Steroidal anti-inflammatory } \\
\text { drugs }\end{array}$ & $\begin{array}{c}\text { Docosanoic acid (DHA), eicosanoid acid (EPA) } \\
\text { Fibrinolytic treatment }\end{array}$ \\
\hline Antioxidants & $\begin{array}{c}\text { Serratiopeptidase, bromelain, escin } \\
\text { Micronutrients }\end{array}$ \\
$\begin{array}{c}\text { Superoxide dismutases, catalase, glutathione peroxidase, glutathione, } \\
\text { N-acetyl-cysteine, vitamin A, vitamin C (ascorbic acid), vitamin E, } \\
\text { coenzyme Q10, carnitine, myoinositol, lycopene, astaxanthin, Serenoa } \\
\text { repens }\end{array}$ \\
\hline
\end{tabular}

TABLE 3: Other antioxidants.

\begin{tabular}{lr}
\hline Amino acids & Arginine, taurine, ornithine, citrulline \\
\hline Vitamins & Vitamins of group B complex, niacin (vitamin PP), pantothenic Acid, folic acid \\
\hline Omega-3 fatty acids & Docosanoic acid (DHA), eicosanoid acid (EPA) \\
\hline & Magnesium, flavonoid, Curcuma longa, Camellia sinensis, Urtica dioica, Lepidium \\
Others & meyenii Walp., Muira Puama(Ptychopetalum olacoides Benth), Ginkgo biloba, \\
& Scutellaria baicalensis, Georgi radix, Pinus massoniana, Cucurbita maxima, \\
Aesculus hippocastanum, Crocus sativus, Epilobium (angustifolium and \\
parviflorum), Citrus bergamia, Orthosiphon, etc.
\end{tabular}

the role of the coadministration of vitamins $\mathrm{E}$ and $\mathrm{C}$ for the improvement of sperm quality in idiopathic male infertility.

The use of NAC, vitamin A, vitamin E, and essential fatty acids in 27 infertile males increases sperm count and decreases ROS and 8-hydroxydeoxyguanine concentration in oligozoospermic patients. Moreover, the treatment improved the acrosome reaction rate and the proportion of PUFA in phospholipids and sperm membrane [167]. In addition, a 26-week-long daily administration of selenium $(200 \mu \mathrm{g})$ and NAC $(600 \mathrm{mg})$ in 468 infertile men with idiopathic asthenozoospermia resulted in an improvement of all sperm parameters. Furthermore, a positive relationship between seminal plasma concentration of NAC and selenium and sperm parameters has been found [168].

List of all available treatments and other antioxidants is shown in Tables 2 and 3.

\section{Other Treatments}

8.1. Pine Bark Extract. The extract of the bark of the (Mediterranean) pine tree, Pinus maritima, is rich in polyphenols, namely, anthocyanidins with antioxidant effect, and it reduces inflammatory reaction through the inhibition of the Cyclooxygenase (COX) enzymes 1 and 2 [106] and of the Nuclear Factor Kappa B (NF-kB). Its potential use can be of interest in order to counteract sperm oxidative stress.

8.2. Lepidium meyenii. Lepidium meyenii, also called maca, is another plant belonging to the cruciferous (Brassica) family, growing in the Peruvian Andes Mountains. It has been considered phytoadaptogen that increases the production of the Heat Shock Protein P 72, by reducing the negative impact of stress on protein conformation and cell death [106]. Moreover, the potential increase of sexual desire induced by this plant without influencing testosterone concentration in adult men could be of importance for male infertility.

8.3. Polyunsaturated Fatty Acids. Polyunsaturated fatty acids have been recommended for nutrition thanks to their several benefits. In fact these fatty acids improve cell membrane fluidity and function, may possibly protect against cardiovascular diseases, and regarding male infertility may be potentially useful for the spermatogenesis $[106,107]$.

\section{Summary}

The identification of etiopathogenetic mechanism(s) allows clinicians to select the optimal treatment to overcome male infertility. The therapeutic repertoire includes antibiotics, anti-inflammatory drugs, antioxidants, and micronutrients. Antibiotics are prescribed when an urogenital infection is identified. The most used antibiotics in clinical practice are quinolones (ciprofloxacin, levofloxacin, etc.), tetracyclines, macrolides, trimethoprim, and $\beta$-lactam antibiotics (penicillin derivatives, cephalosporins, monobactams, and carbapenems). Anti-inflammatory drugs should be given when leukocytospermia and/or inflammatory sign and/or symptoms are present. Finally, antioxidants and micronutrients may be used to protect spermatozoa from oxidative stress overproduction that occurs in many clinical conditions. This class includes a vast array of molecules that may be prescribed alone or in combination. In conclusion, many nonhormonal compounds are available for the treatment of the infertile patient. This allows a customized therapeutic strategy. 


\section{Competing Interests}

The authors declare that there is no conflict of interests regarding the publication of this paper.

\section{References}

[1] M. G. Showell, R. Mackenzie-Proctor, J. Brown, A. Yazdani, M. T. Stankiewicz, and R. J. Hart, "Antioxidants for male subfertility," Cochrane Database of Systematic Reviews, no. 12, Article ID CD007411, 2014.

[2] S. La Vignera, R. A. Condorelli, E. Vicari et al., "Microbiological investigation in male infertility: a practical overview," Journal of Medical Microbiology, vol. 63, no. 1, pp. 1-14, 2013.

[3] S. La Vignera, E. Vicari, R. A. Condorelli et al., "Prevalence of human papilloma virus infection in patients with male accessory gland infection," Reproductive BioMedicine Online, vol. 30, no. 4, pp. 385-391, 2015.

[4] V. Magri, E. Montanari, V. Škerk et al., "Fluoroquinolone-macrolide combination therapy for chronic bacterial prostatitis: retrospective analysis of pathogen eradication rates, inflammatory findings and sexual dysfunctionf," Asian Journal of Andrology, vol. 13, no. 6, pp. 819-827, 2011.

[5] G. Perletti, E. Marras, F. M. E. Wagenlehner, and V. Magri, "Antimicrobial therapy for chronic bacterial prostatitis," Cochrane Database of Systematic Reviews, no. 8, Article ID CD009071, 2013.

[6] World Health Organization, WHO Laboratory Manual for the Examination and Processing of Human Semen, World Health Organization, Geneva, Switzerland, 5th edition, 2010.

[7] E. H. Yanushpolsky, J. A. Politch, J. A. Hill, and D. J. Anderson, "Is leukocytospermia clinically relevant?" Fertility and Sterility, vol. 66, no. 5, pp. 822-825, 1996.

[8] S. La Vignera, R. A. Condorelli, E. Vicari et al., "Markers of semen inflammation: supplementary semen analysis?" Journal of Reproductive Immunology, vol. 100, no. 1, pp. 2-10, 2013.

[9] J. E. Lackner, R. Herwig, J. Schmidbauer, G. Schatzl, C. Kratzik, and M. Marberger, "Correlation of leukocytospermia with clinical infection and the positive effect of antiinflammatory treatment on semen quality," Fertility and Sterility, vol. 86, no. 3, pp. 601-605, 2006.

[10] E. Vicari, C. Rubino, A. De Palma et al., "Antioxidant therapeutic efficiency after the use of carnitine in infertile patients with bacterial or non-bacterial prostato-vesiculo-epididymitis," Archivio Italiano di Urologia e Andrologia, vol. 73, no. 1, p. 15, 2001.

[11] W. Bundrick, S. P. Heron, P. Ray et al., "Levofloxacin versus ciprofloxacin in the treatment of chronic bacterial prostatitis: a randomized double-blind multicenter study," Urology, vol. 62, no. 3, pp. 537-541, 2003.

[12] V. Škerk, S. Schönwald, I. Krhen et al., "Comparative analysis of azithromycin and ciprofloxacin in the treatment of chronic prostatitis caused by Chlamydia trachomatis," International Journal of Antimicrobial Agents, vol. 21, no. 5, pp. 457-462, 2003.

[13] V. Škerk, S. Schönwald, I. Krhen et al., "Comparative analysis of azithromycin and clarithromycin efficacy and tolerability in the treatment of chronic prostatitis caused by Chlamydia trachomatis," Journal of Chemotherapy, vol. 14, no. 4, pp. 384389, 2002.

[14] V. Škerk, I. Krhen, M. Lisić et al., "Comparative randomized pilot study of azithromycin and doxycycline efficacy in the treatment of prostate infection caused by Chlamydia trachomatis,"
International Journal of Antimicrobial Agents, vol. 24, no. 2, pp. 188-191, 2004.

[15] J. H. Jung and J. T. Seo, "Empirical medical therapy in idiopathic male infertility: promise or panacea?" Clinical and Experimental Reproductive Medicine, vol. 41, no. 3, pp. 108-114, 2014.

[16] A. Agarwal, G. Virk, C. Ong, and S. S. du Plessis, "Effect of oxidative stress on male reproduction," The World Journal of Men's Health, vol. 32, no. 1, pp. 1-17, 2014.

[17] A. Agarwal, K. P. Nallella, S. S. R. Allamaneni, and T. M. Said, "Role of antioxidants in treatment of male infertility: an overview of the literature," Reproductive BioMedicine Online, vol. 8, no. 6, pp. 616-627, 2004.

[18] H. M. Fisher and R. J. Aitken, "Comparative analysis of the ability of precursor germ cells and epididymal spermatozoa to generate reactive oxygen metabolites," Journal of Experimental Zoology, vol. 277, no. 5, pp. 390-400, 1997.

[19] R. J. Aitken, "The Amoroso Lecture: the human spermatozoon-a cell in crisis?" Journal of Reproduction and Fertility, vol. 115, no. 1, pp. 1-7, 1999.

[20] E. Gomez, D. W. Buckingham, J. Brindle, F. Lanzafame, D. S. Irvine, and R. J. Aitken, "Development of an image analysis system to monitor the retention of residual cytoplasm by human spermatozoa: correlation with biochemical markers of the cytoplasmic space, oxidative stress, and sperm function," Journal of Andrology, vol. 17, no. 3, pp. 276-287, 1996.

[21] C. S. Opuwari and R. R. Henkel, "An update on oxidative damage to spermatozoa and oocytes," BioMed Research International, vol. 2016, Article ID 9540142, 11 pages, 2016.

[22] F. M. Lanzafame, S. La Vignera, E. Vicari, and A. E. Calogero, "Oxidative stress and medical antioxidant treatment in male infertility," Reproductive BioMedicine Online, vol. 19, no. 5, pp. 638-659, 2009.

[23] R. Walczak-Jedrzejowska, J. K. Wolski, and J. SlowikowskaHilczer, "The role of oxidative stress and antioxidants in male fertility," Central European Journal of Urology, vol. 66, no. 1, pp. 60-67, 2013.

[24] J. Lahdetie, "Occupation- and exposure-related studies on human sperm," Journal of Occupational and Environmental Medicine, vol. 37, no. 8, pp. 922-930, 1995.

[25] P. Thonneau, L. Bujan, L. Multigner, and R. Mieusset, "Occupational heat exposure and male fertility: a review," Human Reproduction, vol. 13, no. 8, pp. 2122-2125, 1998.

[26] J. Słowikowska-Hilczer, "Xenobiotics with estrogen or antiandrogen action-disruptors of the male reproductive system," Central European Journal of Medicine, vol. 1, no. 3, pp. 205-227, 2006.

[27] R. De Celis, N. Pedrón-Nuevo, and A. Feria-Velasco, "Toxicology of male reproduction in animals and humans," Archives of Andrology, vol. 37, no. 3, pp. 201-218, 1996.

[28] A. Agarwal, R. K. Sharma, N. R. Desai, S. Prabakaran, A. Tavares, and E. Sabanegh, "Role of oxidative stress in pathogenesis of varicocele and infertility," Urology, vol. 73, no. 3, pp. 461469, 2009.

[29] M. Grabe, T. E. Bjerklund-Johansen, H. Botto et al., Guidelines on urological infections, European Association of Urology, 2013, http://uroweb.org/wp-content/uploads/18_Urologicalinfections_LR.pdf.

[30] J. Rees, M. Abrahams, A. Doble, and A. Cooper, "Diagnosis and treatment of chronic bacterial prostatitis and chronic prostatitis/chronic pelvic pain syndrome: a consensus guideline," $B J U$ International, vol. 116, no. 4, pp. 509-525, 2016. 
[31] J. S. Wolfson and D. C. Hooper, "Pharmacokinetics of quinolones: newer aspects," European Journal of Clinical Microbiology \& Infectious Diseases, vol. 10, no. 4, pp. 267-274, 1991.

[32] Z.-C. Zhang, F.-S. Jin, D.-M. Liu, Z.-J. Shen, Y.-H. Sun, and Y.L. Guo, "Safety and efficacy of levofloxacin versus ciprofloxacin for the treatment of chronic bacterial prostatitis in Chinese patients," Asian Journal of Andrology, vol. 14, no. 6, pp. 870-874, 2012.

[33] V. Magri, E. Marras, V. Škerk et al., "Eradication of Chlamydia trachomatis parallels symptom regression in chronic bacterial prostatitis patients treated with a fluoroquinolone-macrolide combination," Andrologia, vol. 42, no. 6, pp. 366-375, 2010.

[34] M. M. Oh, J. Y. Chae, J. W. Kim et al., "Positive culture for extended-spectrum $\beta$-lactamase during acute prostatitis after prostate biopsy is a risk factor for progression to chronic prostatitis," Urology, vol. 81, no. 6, pp. 1209-1212, 2013.

[35] J. W. Lancaster, M. V. Mahoney, S. Mandal, and K. R. Lawrence, "Update on treatment options for gonococcal infections," Pharmacotherapy, vol. 35, no. 9, pp. 856-868, 2015.

[36] A. R. A. Abd-Allah, H. A. A. Aly, A. M. A. Moustafa, A.-A. H. Abdel-Aziz, and F. M. A. Hamada, "Adverse testicular effects of some quinolone members in rats," Pharmacological Research, vol. 41, no. 2, pp. 211-219, 2000.

[37] M. A. El-Harouny, A. A. Zalata, M. E. Naser, H. M. Abo El-Atta, I. M. El-Shawaf, and T. Mostafa, "Long-term ofloxacin testicular toxicity: an experimental study," Andrologia, vol. 42, no. 2, pp. 92-96, 2010.

[38] A. C. Singh, M. Kumar, and A. M. Jha, "Genotoxicity of lomefloxacin-an antibacterial drug in somatic and germ cells of Swiss albino mice in vivo," Mutation Research-Genetic Toxicology and Environmental Mutagenesis, vol. 535, no. 1, pp. 35-42, 2003.

[39] E. O. Farombi, M. C. Ugwuezunmba, T. T. Ezenwadu, M. O. Oyeyemi, and M. Ekor, "Tetracycline-induced reproductive toxicity in male rats: effects of vitamin $\mathrm{C}$ and $\mathrm{N}$-acetylcysteine," Experimental and Toxicologic Pathology, vol. 60, no. 1, pp. 77-85, 2008.

[40] J. M. Manson, L. E. Zolna, Y. J. Kang, and C. M. Johnson, "Effects of cefonicid and other cephalosporin antibiotics on male sexual development in rats," Antimicrobial Agents and Chemotherapy, vol. 31, no. 7, pp. 991-997, 1987.

[41] R. P. Singh, K. V. H. Sastry, P. K. Dubey et al., "Norfloxacin drug induces reproductive toxicity and alters androgen receptor gene expression in testes and cloacal gland of male Japanese quail (Coturnix Japonica)," Environmental Toxicology and Chemistry, vol. 32, no. 9, pp. 2134-2138, 2013.

[42] T. Shin, Y. Kobori, K. Suzuki et al., "Inflammatory bowel disease in subfertile men and the effect of mesalazine on fertility," Systems Biology in Reproductive Medicine, vol. 60, no. 6, pp. 373376, 2014.

[43] R. K. Sharma and N. R. Kalla, "Spermatozoal abnormalities and male infertility in the rat following sulfasalazine treatment," International Journal of Fertility and Menopausal Studies, vol. 39, no. 6, pp. 347-354, 1994.

[44] O. Porat-Soldin and S. J. Soldin, "Preliminary studies on the in vitro and in vivo effect of salicylate on sperm motility," Therapeutic Drug Monitoring, vol. 14, no. 5, pp. 366-370, 1992.

[45] F. Roodbari, N. Abedi, and A. R. Talebi, "Early and late effects of ibuprofen on mouse sperm parameters, chromatin condensation, and DNA integrity in mice," International Journal of Reproductive BioMedicine, vol. 13, no. 11, pp. 703-710, 2015.
[46] Á. Vargas, E. Bustos-Obregón, and R. Hartley, "Effects of hypoxia on epididymal sperm parameters and protective role of ibuprofen and melatonin," Biological Research, vol. 44, no. 2, pp. 161-167, 2011.

[47] D. M. Duffy and C. A. VandeVoort, "Maturation and fertilization of nonhuman primate oocytes are compromised by oral administration of a cyclooxygenase- 2 inhibitor," Fertility and Sterility, vol. 95, no. 4, pp. 1256-1260, 2011.

[48] J. H. Kennedy, N. Korn, and R. J. Thurston, "Prostaglandin levels in seminal plasma and sperm extracts of the domestic turkey, and the effects of cyclooxygenase inhibitors on sperm mobility," Reproductive Biology and Endocrinology, vol. 1, article 74, 2003.

[49] J. S. Byun, T. K. Yoon, H. W. Rhee et al., "Chronic pelvic pain syndrome and semen quality of Korean men in their fourth decade," Journal of Andrology, vol. 33, no. 5, pp. 876-885, 2012.

[50] L. Gambera, F. Serafini, G. Morgante, R. Focarelli, V. De Leo, and P. Piomboni, "Sperm quality and pregnancy rate after COX-2 inhibitor therapy of infertile males with abacterial leukocytospermia," Human Reproduction, vol. 22, no. 4, pp. 1047-1051, 2007.

[51] D. Canale, I. Scaricabarozzi, P. Giorgi, P. Turchi, M. Ducci, and G. F. Menchini-Fabris, "Use of a novel non-steroidal anti-inflammatory drug, nimesulide, in the treatment of abacterial prostatovesiculitis," Andrologia, vol. 25, no. 3, pp. 163-166, 1993.

[52] A. P. Ugochukwu, O. O. Ebere, and A. Okwuoma, "Effects of nimesulide on testicular functions in prepubertal albino rats," Journal of Basic and Clinical Physiology and Pharmacology, vol. 22, no. 4, pp. 137-140, 2011.

[53] D. Cui, G. Han, Y. Shang et al., "Antisperm antibodies in infertile men and their effect on semen parameters: a systematic review and meta-analysis," Clinica Chimica Acta, vol. 444, pp. 29-36, 2015.

[54] R. K. Naz, "Modalities for treatment of antisperm antibody mediated infertility: novel perspectives," American Journal of Reproductive Immunology, vol. 51, no. 5, pp. 390-397, 2004.

[55] K. Nakahama, K. Yoshimura, R. Marumoto et al., "Cloning and sequencing of Serratia protease gene," Nucleic Acids Research, vol. 14 , no. 14 , pp. 5843-5855, 1986.

[56] K. Miyata, K. Maejima, K. Tomoda, and M. Isono, "Serratia protease part I. Purification and general properties of the enzyme," Agricultural and Biological Chemistry, vol. 34, no. 2, pp. 310-318, 1970.

[57] N. Moriya, M. Nakata, M. Nakamura et al., "Intestinal absorption of serrapeptase (TSP) in rats," Biotechnology and Applied Biochemistry, vol. 20, no. 1, pp. 101-108, 1994.

[58] N. Moriya, A. Shoichi, H. Yoko, H. Fumio, and K. Yoshiaki, "Intestinal absorption of serrapeptase and its distribution to the inflammation sites," Japanese Pharmacology and Therapeutics, vol. 31, no. 8, pp. 659-666, 2003.

[59] W. H. Kee, S. L. Tan, V. Lee, and Y. M. Salmon, "The treatment of breast engorgement with Serrapeptase (Danzen): a randomised double-blind controlled trial," Singapore Medical Journal, vol. 30, no. 1, pp. 48-54, 1989.

[60] A. Mazzone, M. Catalani, M. Costanzo et al., "Evaluation of serratia peptidase in acute or chronic inflammation of otorhinolaryngology pathology: a multicentre, double-blind, randomized trial versus placebo," Journal of International Medical Research, vol. 18, no. 5, pp. 379-388, 1990.

[61] G. Klein and W. Kullich, "Short-term treatment of painful osteoarthritis of the knee with oral enzymes. A randomised, 
double-blind study versus diclofenac," Clinical Drug Investigation, vol. 19, no. 1, pp. 15-23, 2000.

[62] S. Bhagat, M. Agarwal, and V. Roy, "Serratiopeptidase: a systematic review of the existing evidence," International Journal of Surgery, vol. 11, no. 3, pp. 209-217, 2013.

[63] E. Caroppo, C. Niederberger, P. A. Iacovazzi, M. Correale, and G. D'Amato, "Detection of 90K/MAC-2BP in the seminal plasma of infertile males with accessory gland infection and the autoimmune pathogenetic hypothesis," Journal of Andrology, vol. 27, no. 6, pp. 780-784, 2006.

[64] L. Selan, F. Berlutti, C. Passariello, M. R. Comodi-Ballanti, and M. C. Thaller, "Proteolytic enzymes: a new treatment strategy for prosthetic infections?" Antimicrobial Agents and Chemotherapy, vol. 37, no. 12, pp. 2618-2621, 1993.

[65] S. Sasaki, R. Kawanami, Y. Motizuki et al., "Serrapeptase-induced lung injury manifesting as acute eosiniphilic pneumonia," Nihon Kokyüki Gakkai zasshi, vol. 38, no. 7, pp. 540-544, 2000.

[66] S. J. Taussig and S. Batkin, "Bromelain, the enzyme complex of pineapple (Ananas comosus) and its clinical application: an update," Journal of Ethnopharmacology, vol. 22, no. 2, pp. 191203, 1988.

[67] B. K. Bhattacharyya, "Bromelain: an overview," Indian Journal of Natural Products and Resources, vol. 7, no. 4, pp. 359-363, 2008.

[68] G. Renzini and M. Varego, "Die resorsption von tetrazyklin ingenenwart von Bromelain bei oraler application," Arzneimittel-Forschung Drug Research, vol. 2, pp. 410-412, 1972.

[69] H. R. Maurer, "Bromelain: biochemistry, pharmacology and medical use," Cellular and Molecular Life Sciences, vol. 58, no. 9, pp. 1234-1245, 2001.

[70] S. J. Taussig, "The mechanism of the physiological action of bromelain," Medical Hypotheses, vol. 6, no. 1, pp. 99-104, 1980.

[71] L. P. Hale, "Proteolytic activity and immunogenicity of oral bromelain within the gastrointestinal tract of mice," International Immunopharmacology, vol. 4, no. 2, pp. 255-264, 2004.

[72] K. Chobotova, A. B. Vernallis, and F. A. A. Majid, "Bromelain's activity and potential as an anti-cancer agent: current evidence and perspectives," Cancer Letters, vol. 290, no. 2, pp. 148-156, 2010.

[73] J. V. Castell, G. Friedrich, C.-S. Kuhn, and G. E. Poppe, "Intestinal absorption of undegraded proteins in men: presence of bromelain in plasma after oral intake," American Journal of Physiology_Gastrointestinal and Liver Physiology, vol. 273, no. 1, part 1, pp. G139-G146, 1997.

[74] R. Pavan, S. Jain, Shraddha, and A. Kumar, "Properties and therapeutic application of bromelain: a review," Biotechnology Research International, vol. 2012, Article ID 976203, 6 pages, 2012.

[75] S. Mori, Y. Ojima, T. Hirose, T. Sasaki, and Y. Hashimoto, “The clinical effect of proteolytic enzyme containing bromelain and trypsin on urinary tract infection evaluated by double blind method," Acta Obstetrica et Gynaecologica Japonica, vol. 19, no. 3, pp. 147-153, 1972.

[76] “Bromelain. Monograph," Alternative Medicine Review, vol. 15, no. 4, p. 361, 2010.

[77] S. J. Taussig, M. M. Yokoyama, and A. Chinen, "Bromelain: a proteolytic enzyme and its clinical application: a review," Hiroshima Journal of Medical Sciences, vol. 24, no. 2-3, pp. 185193, 1975.

[78] A. E. Gutfreund, S. J. Taussig, and A. K. Morris, "Effect of oral bromelain on blood pressure and heart rate of hypertensive patients," Hawaii Medical Journal, vol. 37, no. 5, pp. 143-146, 1978.

[79] G. Gailhofer, M. Wilders-Truschnig, J. Smolle, and M. Ludvan, "Asthma caused by bromelain: an occupational allergy," Clinical Allergy, vol. 18, no. 5, pp. 445-450, 1988.

[80] Z. P. Liu, P. Hu, C. H. Li, X. L. Wang, and X. Xiao, "Therapeutic value of aescine in traumatic acute lung injury," Journal of Traumatic Surgery, vol. 15, no. 6, p. 497, 2013.

[81] Y. Wang, W. G. Zhang, L. Jiang, and Q. B. Wang, "Clinical efficacy analysis of sodium ascinate adjuvant in treatment of tibial plateau fracture," Chinese Journal of Biochemical Pharmaceutics, vol. 34, no. 2, pp. 102-104, 2014.

[82] Y. Fang, L. Zhao, F. Yan, X. Xia, D. Xu, and X. Cui, "Escin improves sperm quality in male patients with varicoceleassociated infertility," Phytomedicine, vol. 17, no. 3-4, pp. 192196, 2010.

[83] J. Fujii, Y. Iuchi, S. Matsuki, and T. Ishii, "Cooperative function of antioxidant and redox systems against oxidative stress in male reproductive tissues," Asian Journal of Andrology, vol. 5, no. 3, pp. 231-242, 2003.

[84] R. Peeker, L. Abramsson, and S. L. Marklund, "Superoxide dismutase isoenzymes in human seminal plasma and spermatozoa," Molecular Human Reproduction, vol. 3, no. 12, pp. 10611066, 1997.

[85] M. Ikeda, H. Kodama, J. Fukuda et al., "Role of radical oxygen species in rat testicular germ cell apoptosis induced by heat stress," Biology of Reproduction, vol. 61, no. 2, pp. 393-399, 1999.

[86] A. Kumagai, H. Kodama, J. Kumagai et al., "Xanthine oxidase inhibitors suppress testicular germ cell apoptosis induced by experimental cryptorchidism," Molecular Human Reproduction, vol. 8, no. 2, pp. 118-123, 2002.

[87] M. B. Hosen, M. R. Islam, F. Begum, Y. Kabir, and M. Z. H. Howlader, "Oxidative stress induced sperm DNA damage, a possible reason for male infertility," Iranian Journal of Reproductive Medicine, vol. 13, no. 9, pp. 525-532, 2015.

[88] M. Forouzanfar, A. Abid, S. M. Hosseini, M. Hajian, and M. H. Nasr Esfahani, "Supplementation of sperm cryopreservation media with cell permeable superoxide dismutase mimetic agent (MnTE) improves goat blastocyst formation," Cryobiology, vol. 67, no. 3, pp. 394-397, 2013.

[89] M. Shafiei, M. Forouzanfar, S. M. Hosseini, and M. H. N. Esfahani, "The effect of superoxide dismutase mimetic and catalase on the quality of postthawed goat semen," Theriogenology, vol. 83, no. 8, pp. 1321-1327, 2015.

[90] T. Kobayashi, T. Miyazaki, M. Natori, and S. Nozawa, "Protective role of superoxide dismutase in human sperm motility: superoxide dismutase activity and lipid peroxide in human seminal plasma and spermatozoa," Human Reproduction, vol. 6, no. 7, pp. 987-991, 1991.

[91] S. Sabouhi, Z. Salehi, M. H. Bahadori, and M. Mahdavi, "Human catalase gene polymorphism (CAT C-262T) and risk of male infertility," Andrologia, vol. 47, no. 1, pp. 97-101, 2015.

[92] E. Kawakami, A. Takemura, M. Sakuma et al., "Superoxide dismutase and catalase activities in the seminal plasma of normozoospermic and asthenozoospermic beagles," Journal of Veterinary Medical Science, vol. 69, no. 2, pp. 133-136, 2007.

[93] K. Makker, A. Agarwal, and R. Sharma, "Oxidative stress \& male infertility," Indian Journal of Medical Research, vol. 129, no. 4, pp. 357-367, 2009.

[94] E. Galecka, R. Jacewicz, M. Mrowicka, A. Florkowski, and P. Galecki, "Antioxidative enzymes-structure, properties, functions," Polski Merkuriusz Lekarski, vol. 25, no. 147, p. 266, 2008. 
[95] H. Imai, K. Suzuki, K. Ishizaka et al., "Failure of the expression of phospholipid hydroperoxide glutathione peroxidase in the spermatozoa of human infertile males," Biology of Reproduction, vol. 64, no. 2, pp. 674-683, 2001.

[96] M. Diaconu, Y. Tangat, D. Böhm et al., "Failure of phospholipid hydroperoxide glutathione peroxidase expression in oligoasthenozoospermia and mutations in the PHGPx gene," Andrologia, vol. 38, no. 4, pp. 152-157, 2006.

[97] L. Tripodi, A. Tripodi, C. Mammí, C. Pullé, and F. Cremonesi, "Pharmacological action and therapeutic effects of glutathione on hypokinetic spermatozoa for enzymatic-dependent pathologies and correlated genetic aspects," Clinical and Experimental Obstetrics and Gynecology, vol. 30, no. 2-3, pp. 130-136, 2003.

[98] A. Lenzi, M. Picardo, L. Gandini et al., "Glutathione treatment of dyspermia: effect on the lipoperoxidation process," Human Reproduction, vol. 9, no. 11, pp. 2044-2050, 1994.

[99] D. S. Irvine, "Glutathione as a treatment for male infertility," Reviews of Reproduction, vol. 1, no. 1, pp. 6-12, 1996.

[100] R. F. da Silva, C. dos Santos Borges, P. V. e Silva et al., "The coadministration of $\mathrm{N}$-acetylcysteine ameliorates the effects of arsenic trioxide on the male mouse genital system," Oxidative Medicine and Cellular Longevity, vol. 2016, Article ID 4257498, 11 pages, 2016.

[101] H. Ciftci, A. Verit, M. Savas, E. Yeni, and O. Erel, "Effects of Nacetylcysteine on semen parameters and oxidative/antioxidant status," Urology, vol. 74, no. 1, pp. 73-76, 2009.

[102] E. Cheraghi, M. S. Mehranjani, M. A. Shariatzadeh, M. H. N. Esfahani, and Z. Ebrahimi, "N-Acetylcysteine improves oocyte and embryo quality in polycystic ovary syndrome patients undergoing intracytoplasmic sperm injection: an alternative to metformin," Reproduction, Fertility and Development, vol. 28, no. 6, pp. 723-731, 2016.

[103] G. Livera, V. Rouiller-Fabre, P. Durand, and R. Habert, "Multiple effects of retinoids on the development of Sertoli, germ, and Leydig cells of fetal and neonatal rat testis in culture," Biology of Reproduction, vol. 62, no. 5, pp. 1303-1314, 2000.

[104] M. J. Maya-Soriano, E. Taberner, M. Sabés-Alsina, and M. López-Béjar, "Retinol might stabilize sperm acrosomal membrane in situations of oxidative stress because of high temperatures," Theriogenology, vol. 79, no. 2, pp. 367-373, 2013.

[105] M. K. Al-Azemi, A. E. Omu, T. Fatinikun, N. Mannazhath, and S. Abraham, "Factors contributing to gender differences in serum retinol and $\alpha$-tocopherol in infertile couples," Reproductive BioMedicine Online, vol. 19, no. 4, pp. 583-590, 2009.

[106] F. Comhaire, "The role of food supplementation in the treatment of the infertile couple and for assisted reproduction," Andrologia, vol. 42, no. 5, pp. 331-340, 2010.

[107] F. Comhaire and A. Mahmoud, “The andrologist's contribution to a better life for ageing men: part 2," Andrologia, vol. 48, no. 1, pp. 99-110, 2016.

[108] R. A. Jacob, F. S. Pianalto, and R. E. Agee, "Cellular ascorbate depletion in healthy men," Journal of Nutrition, vol. 122, no. 5 , pp. 1111-1118, 1992.

[109] B. Frei, L. England, and B. N. Ames, "Ascorbate is an outstanding antioxidant in human blood plasma," Proceedings of the National Academy of Sciences of the United States of America, vol. 86, no. 16, pp. 6377-6381, 1989.

[110] T. Doba, G. W. Burton, and K. U. Ingold, "Antioxidant and coantioxidant activity of vitamin C. The effect of vitamin C, either alone or in the presence of vitamin $\mathrm{E}$ or a water-soluble vitamin $\mathrm{E}$ analogue, upon the peroxidation of aqueous multilamellar phospholipid liposomes," Biochimica et Biophysica Acta, vol. 835, no. 2, pp. 298-303, 1985.

[111] M. Mishra and U. R. Acharya, "Protective action of vitamins on the spermatogenesis in lead-treated Swiss mice," Journal of Trace Elements in Medicine and Biology, vol. 18, no. 2, pp. 173178, 2004.

[112] J. J. Thiele, H. J. Freisleben, J. Fuchs, and F. R. Ochsendorf, "Ascorbic acid and urate in human seminal plasma: determination and interrelationships with chemiluminescence in washed semen," Human Reproduction, vol. 10, no. 1, pp. 110-115, 1995.

[113] G. J. Song, E. P. Norkus, and V. Lewis, "Relationship between seminal ascorbic acid and sperm DNA integrity in infertile men," International Journal of Andrology, vol. 29, no. 6, pp. 569575, 2006.

[114] D. D. M. Wayner, G. W. Burton, and K. U. Ingold, "The antioxidant efficiency of vitamin C is concentration-dependent," Biochimica et Biophysica Acta, vol. 884, no. 1, pp. 119-123, 1986.

[115] Y. Wen, T. Cooke, and J. Feely, "The effect of pharmacological supplementation with vitamin $\mathrm{C}$ on low-density lipoprotein oxidation," British Journal of Clinical Pharmacology, vol. 44, no. 1, pp. 94-97, 1997.

[116] M. Levine, C. Conry-Cantilena, Y. Wang et al., "Vitamin C pharmacokinetics in healthy volunteers: evidence for a recommended dietary allowance," Proceedings of the National Academy of Sciences of the United States of America, vol. 93, no. 8, pp. 3704-3709, 1996.

[117] E. B. Dawson, W. A. Harris, M. C. Teter, and L. C. Powell, "Effect of ascorbic acid supplementation on the sperm quality of smokers," Fertility and Sterility, vol. 58, no. 5, pp. 1034-1039, 1992.

[118] B. Eskenazi, S. A. Kidd, A. R. Marks, E. Sloter, G. Block, and A. J. Wyrobek, "Antioxidant intake is associated with semen quality in healthy men," Human Reproduction, vol. 20, no. 4, pp. 10061012, 2005.

[119] E. Kessopoulou, H. J. Powers, K. K. Sharma et al., "A doubleblind randomized placebo cross-over controlled trial using the antioxidant vitamin $\mathrm{E}$ to treat reactive oxygen species associated male infertility," Fertility and Sterility, vol. 64, no. 4, pp. 825-831, 1995.

[120] J. Moilanen and O. Hovatta, "Excretion of alpha-tocopherol into human seminal plasma after oral administration," Andrologia, vol. 27, no. 3, pp. 133-136, 1995.

[121] P. Thérond, J. Auger, A. Legrand, and P. Jouannet, “ $\alpha$-tocopherol in human spermatozoa and seminal plasma: relationships with motility, antioxidant enzymes and leukocytes," Molecular Human Reproduction, vol. 2, no. 10, pp. 739-744, 1996.

[122] P. Giovenco, M. Amodei, C. Barbieri, R. Fasani, M. Carosi, and F. Dondero, "Effects of kallikrein on the male reproductive system and its use in the treatment of idiopathic oligozoospermia with impaired motility," Andrologia, vol. 19, pp. 238-241, 1987.

[123] J. Moilanen, O. Hovatta, and L. Lindroth, "Vitamin E levels in seminal plasma can be elevated by oral administration of vitamin $\mathrm{E}$ in infertile men," International Journal of Andrology, vol. 16, no. 2, pp. 165-166, 1993.

[124] E. Geva, B. Bartoov, N. Zabludovsky, J. B. Lessing, L. LernerGeva, and A. Amit, "The effect of antioxidant treatment on human spermatozoa and fertilization rate in an in vitro fertilization program," Fertility and Sterility, vol. 66, no. 3, pp. 430-434, 1996.

[125] S. A. Suleiman, M. E. Ali, Z. M. S. Zaki, E. M. A. El-Malik, and M. A. Nasr, "Lipid peroxidation and human sperm motility: 
protective role of vitamin E," Journal of Andrology, vol. 17, no. 5, pp. 530-537, 1996.

[126] A. Gvozdjáková, J. Kucharská, J. Dubravicky, V. Mojto, and R. B. Singh, "Coenzyme $\mathrm{Q}_{10}, \alpha$-tocopherol, and oxidative stress could be important metabolic biomarkers of male infertility," Disease Markers, vol. 2015, Article ID 827941, 6 pages, 2015.

[127] G. Balercia, E. Buldreghini, A. Vignini et al., "Coenzyme Q10 treatment in infertile men with idiopathic asthenozoospermia: a placebo-controlled, double-blind randomized trial," Fertility and Sterility, vol. 91, no. 5, pp. 1785-1792, 2009.

[128] M. R. Safarinejad, "Efficacy of coenzyme Q10 on semen parameters, sperm function and reproductive hormones in infertile men," The Journal of Urology, vol. 182, no. 1, pp. 237-248, 2009.

[129] M. R. Safarinejad, "The effect of coenzyme Q 10 supplementation on partner pregnancy rate in infertile men with idiopathic oligoasthenoteratozoospermia: an open-label prospective study," International Urology and Nephrology, vol. 44, no. 3, pp. 689-700, 2012.

[130] A. Mancini, G. Conte, D. Milardi, L. de Marinis, and G. P. Littarru, "Relationship between sperm cell ubiquinone and seminal parameters in subjects with and without varicocele," Andrologia, vol. 30, no. 1, pp. 1-4, 1998.

[131] A. Agarwal and T. M. Said, "Carnitines and male infertility," Reproductive BioMedicine Online, vol. 8, no. 4, pp. 376-384, 2004.

[132] M. N. Chiu, M. R. Blackman, C. Wang, and R. S. Swerdloff, "The role of carnitine in the male reproductive system," Annals of the New York Academy of Sciences, vol. 1033, pp. 177-188, 2004.

[133] A. Lenzi, F. Lombardo, L. Gandini, and F. Dondero, "[Metabolism and action of L-carnitine: its possible role in sperm tail function]," Archivio Italiano di Urologia Nefrologia Andrologia, vol. 64, no. 2, pp. 187-196, 1992.

[134] M. S. Bornman, D. du Toit, B. Otto, I. I. Muller, P. Hurter, and D. J. du Plessis, "Seminal carnitine, epididymal function and spermatozoal motility," South African Medical Journal, vol. 75, no. 1, pp. 20-21, 1989.

[135] T. G. Cooper, W. Weidner, and E. Nieschlag, "The influence of inflammation of the human male genital tract on secretion of the seminal markers $\alpha$-glucosidase, glycerophosphocholine, carnitine, fructose and citric acid," International Journal of Andrology, vol. 13, no. 5, pp. 329-336, 1990.

[136] E. Vicari, S. La Vignera, and A. E. Calogero, "Antioxidant treatment with carnitines is effective in infertile patients with prostatovesiculoepididymitis and elevated seminal leukocyte concentrations after treatment with nonsteroidal anti-inflammatory compounds," Fertility and Sterility, vol. 78, no. 6, pp. 1203-1208, 2002.

[137] M. L. Moncada, E. Vicari, C. Cimino, A. E. Calogero, A. Mongioì, and R. D’Agata, "Effect of acetylcarnitine treatment in oligoasthenospermic patients," Acta Europaea Fertilitatis, vol. 23, no. 5, pp. 221-224, 1992.

[138] M. Costa, D. Canale, M. Filicori, S. D’lddio, and A. Lenzi, "L-carnitine in idiopathic asthenozoospermia: a multicenter study," Andrologia, vol. 26, no. 3, pp. 155-159, 1994.

[139] G. Vitali, R. Parente, and C. Melotti, "Carnitine supplementation in human idiopathic asthenospermia: clinical results," Drugs under Experimental and Clinical Research, vol. 21, no. 4, pp. 157-159, 1995.

[140] E. Vicari and A. E. Calogero, "Effects of treatment with carnitines in infertile patients with prostato-vesiculo-epididymitis," Human Reproduction, vol. 16, no. 11, pp. 2338-2342, 2001.
[141] A. Lenzi, F. Lombardo, P. Sgrò et al., "Use of carnitine therapy in selected cases of male factor infertility: a double-blind crossover trial," Fertility and Sterility, vol. 79, no. 2, pp. 292-300, 2003.

[142] A. Lenzi, P. Sgrò, P. Salacone et al., "A placebo-controlled double-blind randomized trial of the use of combined Lcarnitine and L-acetyl-carnitine treatment in men with asthenozoospermia," Fertility and Sterility, vol. 81, no. 6, pp. 15781584,2004

[143] G. Balercia, F. Regoli, T. Armeni, A. Koverech, F. Mantero, and M. Boscaro, "Placebo-controlled double-blind randomized trial on the use of L-carnitine, L-acetylcarnitine, or combined Lcarnitine and L-acetylcarnitine in men with idiopathic asthenozoospermia," Fertility and Sterility, vol. 84, no. 3, pp. 662-671, 2005.

[144] M. De Rosa, B. Boggia, B. Amalfi et al., "Correlation between seminal carnitine and functional spermatozoal characteristics in men with semen dysfunction of various origins," Drugs in $R$ and D, vol. 6, no. 1, pp. 1-9, 2005.

[145] S. Banihani, A. Agarwal, R. Sharma, and M. Bayachou, "Cryoprotective effect of l-carnitine on motility, vitality and DNA oxidation of human spermatozoa," Andrologia, vol. 46, no. 6, pp. 637-641, 2014.

[146] R. A. Condorelli, S. Lavignera, F. Di Bari, V. Unfer, and A. E. Calogero, "Effects of myoinositol on sperm mitochondrial function in-vitro," European Review for Medical and Pharmacological Sciences, vol. 15, no. 2, pp. 129-134, 2011.

[147] R. A. Condorelli, S. La Vignera, S. Bellanca, E. Vicari, and A. E. Calogero, "Myoinositol: does it improve sperm mitochondrial function and sperm motility?" Urology, vol. 79, no. 6, pp. 12901295, 2012.

[148] A. E. Calogero, G. Gullo, S. La Vignera, R. A. Condorelli, and A. Vaiarelli, "Myoinositol improves sperm parameters and serum reproductive hormones in patients with idiopathic infertility: a prospective double-blind randomized placebocontrolled study," Andrology, vol. 3, no. 3, pp. 491-495, 2015.

[149] F. A. Gulino, E. Leonardi, I. Marilli et al., "Effect of treatment with myo-inositol on semen parameters of patients undergoing an IVF cycle: in vivo study," Gynecological Endocrinology, vol. 32, no. 1, pp. 65-68, 2016.

[150] N. P. Gupta and R. Kumar, "Lycopene therapy in idiopathic male infertility-a preliminary report," International Urology and Nephrology, vol. 34, no. 3, pp. 369-372, 2002.

[151] Z. W. Liang, K. M. Guo, X. F. Dai et al., "Protective effect of lycopene on human spermatozoa during cryopreservation and its mechanism," Zhonghua Nan Ke Xue, vol. 21, no. 6, pp. 521$526,2015$.

[152] D. Durairajanayagam, A. Agarwal, C. Ong, and P. Prashast, "Lycopene and male infertility," Asian Journal of Andrology, vol. 16, no. 3, pp. 420-425, 2014.

[153] F. H. Comhaire, Y. El Garem, A. Mahmoud, F. Eertmans, and F. Schoonjans, "Combined conventional/antioxidant," Asian Journal of Andrology, vol. 7, no. 3, pp. 257-262, 2005.

[154] M. Mortazavi, I. Salehi, Z. Alizadeh, M. Vahabian, and A. M. Roushandeh, "Protective effects of antioxidants on sperm parameters and seminiferous tubules epithelium in high fat-fed rats," Journal of Reproduction and Infertility, vol. 15, no. 1, pp. 22-28, 2014.

[155] R. MacDonald, J. W. Tacklind, I. Rutks, and T. J. Wilt, "Serenoa repens monotherapy for benign prostatic hyperplasia $(\mathrm{BPH})$ : an updated Cochrane systematic review," BJU International, vol. 109, no. 12, pp. 1756-1761, 2012. 
[156] A. Latil, M.-T. Pétrissans, J. Rouquet, G. Robert, and A. de la Taille, "Effects of hexanic extract of Serenoa repens (Permixon ${ }^{\circledR}$ $160 \mathrm{mg}$ ) on inflammation biomarkers in the treatment of lower urinary tract symptoms related to benign prostatic hyperplasia," Prostate, vol. 75, no. 16, pp. 1857-1867, 2015.

[157] R. R. Ondrizek, P. J. Chan, W. C. Patton, and A. King, "Inhibition of human sperm motility by specific herbs used in alternative medicine," Journal of Assisted Reproduction and Genetics, vol. 16, no. 2, pp. 87-91, 1999.

[158] R. R. Ondrizek, P. J. Chan, W. C. Patton, and A. King, "An alternative medicine study of herbal effects on the penetration of zona-free hamster oocytes and the integrity of sperm deoxyribonucleic acid," Fertility and Sterility, vol. 71, no. 3, pp. 517-522, 1999.

[159] F. Atig, M. Raffa, H. B. Ali, K. Abdelhamid, A. Saad, and M. Ajina, "Altered antioxidant status and increased lipid peroxidation in seminal plasma of Tunisian infertile men," International Journal of Biological Sciences, vol. 8, no. 1, pp. 139-149, 2011.

[160] A. Agarwal and L. H. Sekhon, "Oxidative stress and antioxidants for idiopathic oligoasthenoteratospermia: is it justified," Indian Journal of Urology, vol. 27, no. 1, pp. 74-85, 2011.

[161] M. H. Hadwan, L. A. Almashhedy, and A. R. S. Alsalman, "Oral zinc supplementation restores superoxide radical scavengers to normal levels in spermatozoa of Iraqi asthenospermic patients," International Journal for Vitamin and Nutrition Research, vol. 85, no. 3-4, pp. 165-173, 2015.

[162] M. Tabassomi and S. M. Alavi-Shoushtari, "Effects of in vitro copper sulphate supplementation on the ejaculated sperm characteristics in water buffaloes (Bubalus bubalis)," Veterinary Research Forum, vol. 4, no. 1, pp. 31-36, 2013.

[163] A. V. Lyubimov, J. A. Smith, S. D. Rousselle et al., "The effects of tetrathiomolybdate (TTM, NSC-714598) and copper supplementation on fertility and early embryonic development in rats," Reproductive Toxicology, vol. 19, no. 2, pp. 223-233, 2004.

[164] E. Greco, M. Iacobelli, L. Rienzi, F. Ubaldi, S. Ferrero, and J. Tesarik, "Reduction of the incidence of sperm DNA fragmentation by oral antioxidant treatment," Journal of Andrology, vol. 26, no. 3, pp. 349-353, 2005.

[165] E. Greco, S. Romano, M. Iacobelli et al., "ICSI in cases of sperm DNA damage: beneficial effect of oral antioxidant treatment," Human Reproduction, vol. 20, no. 9, pp. 2590-2594, 2005.

[166] C. Castellini, P. Lattaioli, M. Bernardini, and A. Dal Bosco, "Effect of dietary $\alpha$-tocopheryl acetate and ascorbic acid on rabbit semen stored at $5{ }^{\circ} \mathrm{C}$," Theriogenology, vol. 54 , no. 4 , pp. 523-533, 2000.

[167] F. H. Comhaire, A. B. Christophe, A. A. Zalata, W. S. Dhooge, A. M. A. Mahmoud, and C. E. Depuydt, "The effects of combined conventional treatment, oral antioxidants and essential fatty acids on sperm biology in subfertile men," Prostaglandins Leukotrienes and Essential Fatty Acids, vol. 63, no. 3, pp. 159$165,2000$.

[168] M. R. Safarinejad and S. Safarinejad, "Efficacy of selenium and/or N-acetyl-cysteine for improving semen parameters in infertile men: a double-blind, placebo controlled, randomized study," The Journal of Urology, vol. 181, no. 2, pp. 741-751, 2009. 


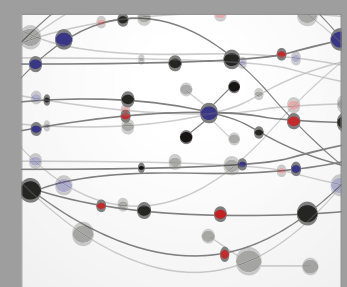

The Scientific World Journal
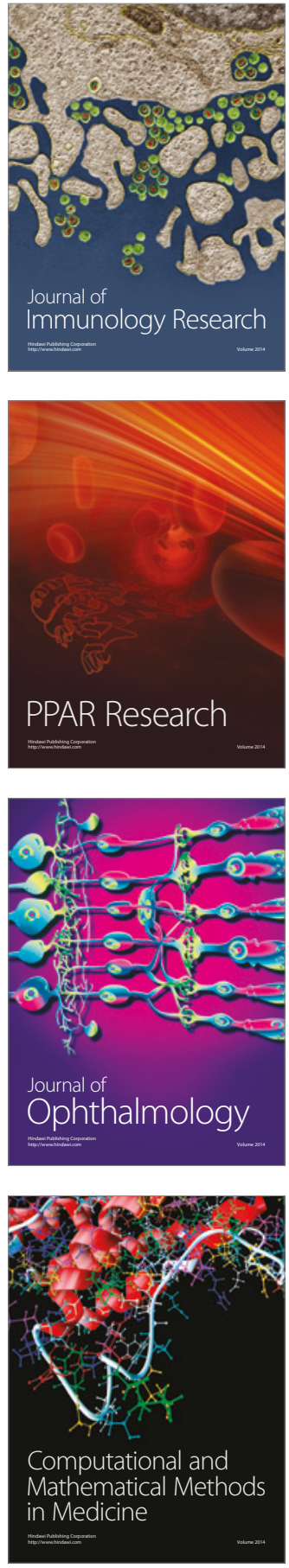

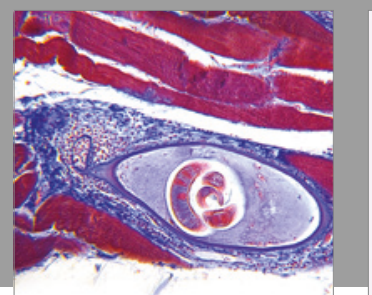

Gastroenterology Research and Practice
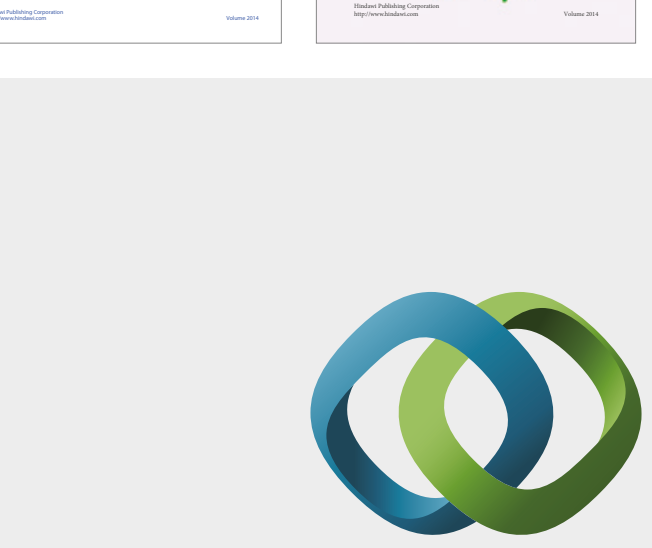

\section{Hindawi}

Submit your manuscripts at

https://www.hindawi.com
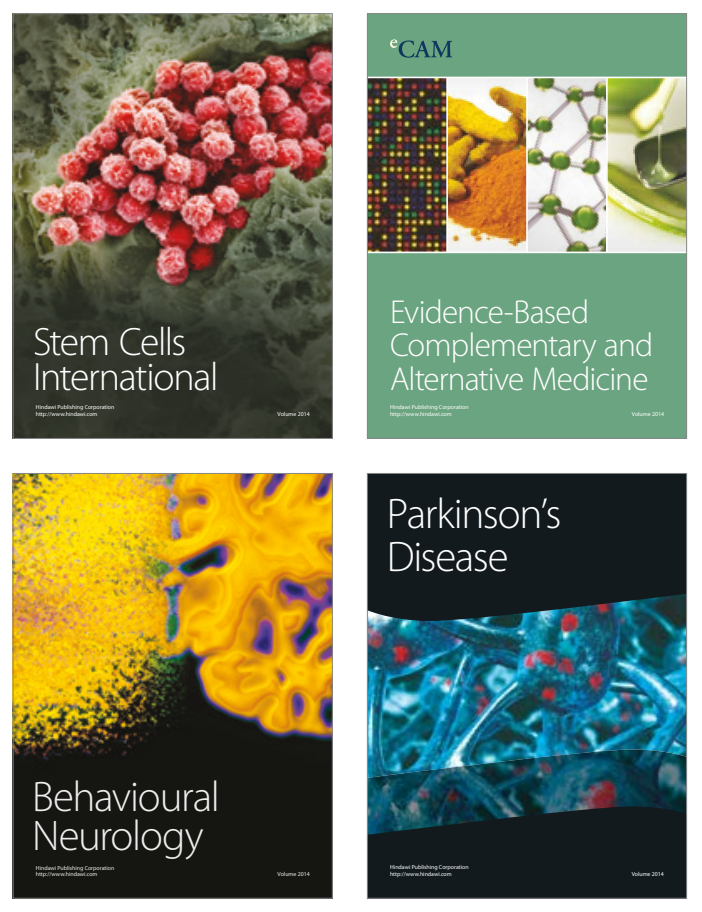
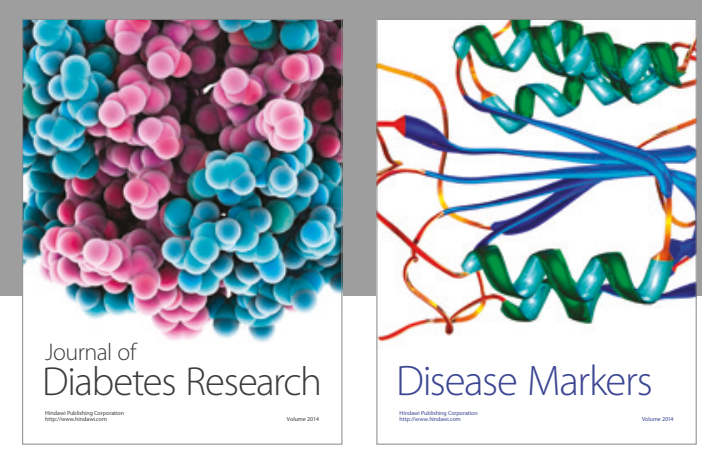

Disease Markers
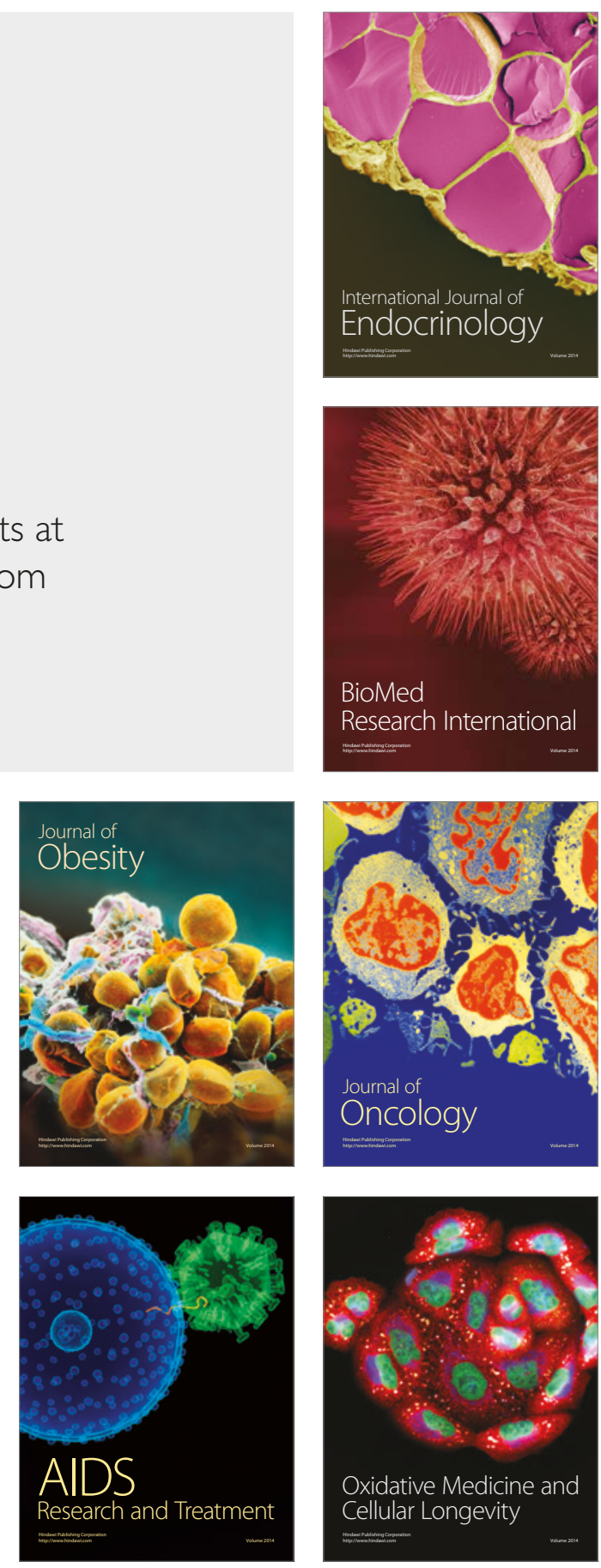